\title{
When Technology Cares for People with Dementia: \\ A Critical Review using Neuropsychological Rehabilitation as a Conceptual Framework
}

Carlo Fabricatore ${ }^{1}$, Darinka Radovic ${ }^{2}$, Ximena Lopez ${ }^{1}$, Aitana Grasso-Cladera ${ }^{3}$ \& Christian E. Salas ${ }^{34}$

${ }^{1}$ School of Computing and Engineering, University of Huddersfield, Huddersfield, UK

${ }^{2}$ Centro de Modelamiento Matemático, Universidad de Chile, Santiago, Chile.

${ }^{3}$ Laboratorio de Neurociencia Cognitiva y Social, LANCyS, Facultad de Psicología, Universidad Diego Portales, Santiago, Chile.

${ }^{4}$ Unidad de Neuropsicología Clínica, Facultad de Psicología, Universidad Diego Portales, Santiago, Chile.

Correspondence should be addressed to: Christian E. Salas, Facultad de Psicología, Universidad Diego Portales, Vergara 275, Santiago, Chile

Email: christian.salas@udp.cl

This work was supported by the University of Huddersfield, under grants URF301-01 and URF506-01. 


\section{When Technology Cares for People with Dementia: \\ A Critical Review using Neuropsychological Rehabilitation as a Conceptual Framework}

During the last decade clinicians and researchers have become increasingly interested in the potential of technology in assisting persons with dementia (PwD). However, several issues have emerged in relation to how studies and reviews have conceptualized who the main technology user is (PwD and/or carer), how technology is used (as compensatory, environment modification, monitoring or retraining tool), why it is used (i.e. what impairments and/or disabilities are supported) and what variables have been considered as relevant to support engagement with technology. In this review we adopted a Neuropsychological Rehabilitation perspective to analyze 253 studies reporting on technological solutions for PwD. We analyzed purposes/uses, supported impairments and disabilities and how engagement was (or was not) considered. Findings showed that the most frequent purposes of technology use were compensation and monitoring, supporting orientation, sequencing complex actions and memory impairments in a wide range of activities. The few studies that addressed the issue of engagement with technology considered how the ease of use, social appropriateness, features of emotion-regulation, level of personalization, dynamic adaptation and carers' mediation allowed technology to adapt to PWD's and carers' preferences and performance. Conceptual and methodological tools emerged as outcomes of the analytical process, representing an important contribution to understanding the role of technologies to increase PwD's wellbeing and orient future research.

Keywords: Technology; dementia; Neuropsychological Rehabilitation; assistive technologies for cognition; engagement 
There is a requirement for a tap water control that acts like the carer, and which does not take control away from the user. (Orpwood, Gibbs, Adlam, Faulkner \& Meegahawatte, 2005)

\section{Introduction}

Dementia is defined as a clinical syndrome characterized by progressive deterioration in multiple cognitive domains which is severe enough to interfere with daily functioning (Qiu \& Fratiglioni, 2011). It encompasses a number of different progressive neurological conditions, such as Alzheimer's disease, vascular dementia and dementia with Lewy bodies, amongst other less frequent sub-types (Clare, 2008). Due to multiple cognitive deficits, persons with dementia $(\mathrm{PwD})$ require increasing support and assistance in order to perform activities of daily living (ADLs). As the condition progresses, PwD and their carers/relatives commonly need to deal with problems such as forgetfulness, disorientation, risk of injury or poor medication management (Georges et al., 2008; Liu et al., 2007). In the last 15 years clinicians and researchers working with PwD have become increasingly interested in the use of technology as a tool to reduce the impact of cognitive impairment in ADLs. Although the adoption of new technologies is frequently challenging, several studies have offered evidence to support the value of technological tools for PwD, in terms of increasing their independence, safety and wellbeing (Cahill, Begley, Faulkner \& Hagen, 2007; Topo, 2009).

Due to a large number of studies on the topic of technology use and dementia, since 2009 three comprehensive reviews of historical relevance to the field have attempted to systematize the available information, with rather dissimilar outcomes ${ }^{1}$. Bharucha and colleagues (2009) reported that most available technological solutions in the market were not specifically designed for PwD, and the only three studies involving dementia subjects "relied on small samples and varied in methodological rigor" (p. 100). The same year, Topo (2009) reported a considerably larger number of studies $(\mathrm{N}=66)$ using technological solutions for both the assessment and treatment of PwD. The author concluded that more than half of the studies had as a main goal the use of technology to improve wellbeing and independence, predominantly in the context of residential care. More importantly, most of the studies focused on the needs of the caregivers, while less than a quarter of them actually explored

\footnotetext{
${ }^{1}$ There are other reviews which we will not consider here since they are topic-specific rather than comprehensive, targeting the use of technology to address particular problems of PwD (e.g. memory).
} 
how PwD used technologies. Finally, Evans and colleagues in 2015 reported a total of over 170 studies. An interesting finding of this review was the overrepresentation of compensatory memory aids to improve ADLs and safety devices compared to the limited number of studies using technology to improve leisure activities. These three reviews have advanced important knowledge regarding how technologies are used to support PwD and their carers. However, they present limitations concerning the conceptualization of the deficits targeted by technological solutions, their intervention purpose, and the facilitation of their adoption and use. These limitations bear important implications for clinical practice as well as technological research and development.

The field of Neuropsychological Rehabilitation (NR) provides an encompassing theoretical framework that can help conceptualizing why and how technologies are/can be used to support PwD. Prior research has highlighted that NR is as relevant for PwD as it is for people with non-progressive brain injury, since it provides a general framework for interventions and a means of tackling specific cognitive and emotional issues that arise as a consequence of neurological and neuropsychological impairments (Clare, 2005; Choi \& Twamley, 2013). It has been highlighted in the field of NR that technology is an important tool for reducing everyday problems of people with neurological damage (LoPresti, Mihailidis \& Kirsch, 2004; Wilson, 2008). To our knowledge the NR framework has not been used as an analytical perspective to investigate technology-based interventions. However, we argue that the aforementioned limitations can be conceptualized and tackled by leveraging NR perspectives as follows:

\subsection{Classification of the main technology user}

PwD and their psychosocial support systems are often considered as crucial participants of any NR endeavor, and their involvement usually implies different roles and degrees of participation (Choi \& Twamley, 2013). One important conceptual limitation of the aforementioned reviews is the loose classification of studies in terms of who the main technology user is. An example of this problem can be found in the review by Topo (2009), who considered that a PwD was "involved" in the use of a technology if they agreed "to wear a technology such as a transmitter of a monitoring system, at least to monitor physical activity even if not actively influence its functioning and act as informants" (p. 19). In this example it is at least debatable whether agreeing to use a technology or offering verbal reports about it, represent a form of active involvement sufficient to consider the PwD as the main user. O’Neill and Gillespie (2015) have argued that assistive technology must enable, 
enhance or extend cognitive function when used. Monitoring technologies, in contrast, offer information about the state of the user but do not feed this back to him/her. Similarly, Gibson and colleagues (2016) have proposed that technologies could be classified based on whether they are used 'by' PwD, 'with' PwD or 'on' PwD.

\subsection{Conceptualization and analysis of the intervention purpose of technological solutions}

Dementia technologies can be used to fulfill different purposes in order to ameliorate PwD's deficits, for example by training cognitive functions or directly mediating ADLs (Bharucha et al., 2009; Topo, 2009; Evans et al., 2015). A systematic classification of such purposes can help understanding how technology can be used and support the design of new technologies for specific purposes. Previous reviews have not accounted for such purposes, focusing on often general and non-systematic descriptions of the objectives accomplished by technological solutions. Based on the categorization of interventions in NR proposed by Mateer \& Sholberg (2003), it can be argued that technologies can ameliorate cognitive deficits and improve everyday functioning via retraining (improving cognitive functions through practice and stimulation), compensating deficits (using residual skills and external support to carry out a task despite the presence of cognitive impairment) or modifying the environment (decreasing the cognitive load of certain tasks to optimize PwD's functioning).

\subsection{Definition and analysis of the deficits targeted by technological solutions}

In order to fully comprehend the scope of a technological solution, this should be analyzed accounting for the cognitive deficits targeted, as much as for the consequences that these deficits may have on relevant activity contexts -disabilities. As noted by Wilson (1997), a confusion of levels may compromise the possibility of performing comparative analyses between different solutions. The aforementioned reviews have not accounted for the multilevel nature of the objectives of a technological solution, thus conflating levels of analysis. NR commonly defines the objectives of an intervention in accordance with the International Classification of Functioning, Disability and Health (ICF, WHO, 1980), which categorizes the sequalae of a neurological condition as impairments (damage to physical or mental structures, e.g. language impairment), disabilities (restriction or lack of ability to perform an activity, e.g. sustain a conversation) and handicaps (impact that impairments and disability have on participation in purposeful daily activities, e.g. work).

\subsection{Engagement with technology: conceptualization and analysis of factors facilitating the adoption and use of technological solutions}

A central issue that emerges when considering the use of assistive technologies for cognition 
in PwD is how they engage with technology, and how the designed technological solutions facilitate this engagement process. For any technology to have an impact on wellbeing through its use, PwD must first be capable and willing to interact with the technology. There is abundant literature describing how, due to cognitive impairments, $\mathrm{PwD}$ become passive, which often leads to withdrawal from instrumental, social and life-style activities (Kolanowski \& Buettner, 2008; Paillard- Borg et al, 2009; Edvardsson et al, 2013; Fernandez-Mayoralas et al, 2015). This emphasizes engagement with technology as a critical process to attend, since cognitive difficulties could impact both the PwD's ability to interact with technology, as well as his/her motivation to remain engaged with it. None of the existing reviews have examined the literature paying attention to this variable.

\section{Objectives and Scope of this Review}

In light of the above-discussed limitations of previous reviews, the main goal of this study is to critically examine the available literature on dementia and technology using an NR framework to guide the coding, analysis and interpretation of data. More specifically, this review will explore four questions that address the limitations discussed in the previous section:

(1) Question 1 (Classification of the main technology user): Who has been identified as active user(s) of the technological solutions developed for PwD?

(2) Question 2 (Purpose of technological solutions): Considering the main intervention approaches proposed by the NR framework, what intervention purposes have been sought by previous studies through the use of technological solutions?

(3) Question 3 (Types of impairments and disabilities addressed by technology): Which types of impairments and disabilities are commonly addressed by available technologies for PwD?

(4) Question 4 (Conceptualization of engagement of PwD with technology): How have studies addressed engagement, and what strategies have been implemented for its facilitation?

\section{Methodology}

\subsection{Literature search procedure}

This literature review followed PRISMA guidelines (Moher, Liberti, Tetzlaff \& Altman, 2009). However, since the focus of this article was to map available technological solutions 
using an NR framework, no assessment of evidence was carried out. Studies were included in this review if they focused on the use of any technological solution for assisting or supporting the various cognitive/socio-emotional needs of PwD. Articles were searched using a pool of keywords based on previous reviews: (dementia OR Alzheimer) AND (assistive technology OR adaptive technology OR adaptive system OR context-aware computing OR affective computing OR assistive device OR monitoring OR surveillance OR tracking OR smart homes). Keywords search was performed as "topic" or in "all field" in four relevant databases: PsychINFO, Medline, Pubmed, and Web of Science. In addition, we surveyed every study included in previous reviews, including Bharucha and colleagues (2009), Topo (2009) and Evans and colleagues (2015). This was an all-time search until 2015 and included only English written studies. A total of 4356 articles from data bases and 290 articles from previous reviews were initially identified. Key information on these articles was consolidated in a database, including authors, title, source and abstract. Articles were then selected for full revision through a two-step process (see Fig. 1).

Insert here Fig. 1

As a first step, titles and abstracts were screened in order to exclude duplicated articles and those that were not related to technological interventions for PwD. The main exclusion criteria were: a) articles that did not refer to any form of dementia; b) articles that did not mention any technology-related concept. As a second step, titles and abstracts of the included articles were reviewed again, in order to check the eligibility as defined (studies reporting on technological interventions for PwD). Thus, studies were excluded if they: a) focused on other uses of technology (e.g. to determine causes of dementia, to contribute to the diagnosis or pharmacological treatment of dementias); or b) explored general technological solutions which were not part of a specific intervention. We also excluded literature reviews and theoretical articles.

\subsection{Analysis}

Two reviewers coded the final 253 articles focusing on the description of the technological solution and its function in addressing specific cognitive deficits and associated functional impairments in ADLs. General information on the studies was also coded and extracted, including: purpose of the study (e.g. development or design of a technological solution, evaluation of an intervention); context (home, residential care home facility, institution); 
research design characteristics (e.g. methodology used, sample, etc.); and level of dementia (mild, moderate, severe, mixed).

In order to respond to question 1, the main technology user was coded as patient, carer or both, based on who was the main recipient of information provided by the technological solution, and/or who was its main operator. Technologies that did not target a main information recipient, nor had a main operator, were coded as "no main technology user".

In relation to question 2, using the classification proposed by Mateer and Sohlberg (2003), each technological intervention was coded as cognitive retraining, compensation or environment modification. Monitoring, carer support and activity recognition also emerged from the coding process as relevant categories.

As for question 3, each technological solution was coded in terms of the impairment/deficit it attempted to address (e.g. spatial disorientation) and the disability/ADL impact originated by such impairment (e.g. way-finding). The classification of cognitive impairments provided by O'Neill and Gillespie (2015) was adapted to guide the coding process (e.g. memory, time and place orientation, sequencing complex actions). Due to the large number of possible disabilities an open coding approach with iterative refinement was adopted to analyze types of impairments in relation to disabilities.

Since engagement was conceptualized as a form of active involvement of the PwD with technology, in order to respond to question 4 , the search was firstly narrowed to articles where the PwD was actively involved with the technological solution (total sub-sample of 138 studies). The coders then reviewed the methodology section and description of the technological solution in each one of these studies, looking for explicit references to adaptations/features highlighted as factors that can promote and facilitate technology use by PwD. Descriptions of the adaptations/features were extracted from the selected articles, consolidated in a database and subjected to an iterative open coding process. This led to the formulation of general categories of factors facilitating engagement with technology.

\section{Results}

A first general result of our review is the growing number of publications on this topic, a number that has increased almost eightfold since 2000 (Fig. 2). Half of the studies developed technological solutions to be used at home $(\mathrm{n}=128,51 \%)$. Only $48(19 \%)$ of the reviewed studies reported the use of technology in care home facilities. In this setting, just under half of the studies $(n=23)$ had the carer as the main technology user, and the main goal of 
interventions was to monitor the behavior of the PwD. Finally, it is important to note that a considerable number of studies $(n=77,30 \%)$ described technological solutions that could be used either at home or in nursing homes.

Insert here Fig. 2

A large number of papers did not report the level of dementia which the technological solution was designed for $(n=113,44 \%)$. Most of the studies that considered the level of dementia as relevant for their designs focused on addressing needs of people with mild or moderate cognitive deficits, or at the initial stages of the illness $(n=83,33 \%)$. Only $10 \%(n$ $=25$ ) of reviewed studies focused on technology developed for patients with moderate-severe or at late stages of the disease.

\subsection{Classification of the main technology user (Question 1)}

Data from this review suggests that most technological solutions considered the PwD as an active technology user. Just under half of the studies $(n=109,43 \%)$ reported technologies that directly feed information to the PwD in order to facilitate the accomplishment of an activity, thus enhancing, enabling or extending cognitive functions ( $\mathrm{O}$ 'Neill \& Gillespie, 2015). A further $12 \%$ of the studies reviewed $(n=29)$ described interventions that actively engaged both carers and PwD, 33\% $(n=84)$ had carers as the exclusive users of the technological solutions.

\subsection{Conceptualization of the purpose of technological solutions (Question 2)}

We coded 315 different purposes based on the NR conceptualization of interventions proposed by Mateer \& Sholberg (2003), and found that $62 \%$ of the reviewed studies described technologies focused on compensating, retraining, modifying the environment or a combination of them (see Table 1).

\section{Insert here Table 1}

Technological solutions were most frequently used as tools to compensate cognitive deficits, allowing PwD to reduce the impact of a wide variety of cognitive impairments on the successful accomplishment of meaningful everyday activities $(\mathrm{n}=131,52 \%)$. The large number of studies using technology as a compensatory tool contrasts with a considerably 
smaller number of cases in which technological solutions were employed to modify the environment (e.g. stove timers used to prevent gas leaks, 19 studies, $8 \%$ ) or to retrain cognitive functions (e.g. computer programs, 18 studies, 7\%).

A considerable number of studies conceptualized the purpose of technological solutions outside the classic scope of NR. Monitoring is the best example, since 33\% ( $n=84)$ of the studies reviewed used technology with such purpose. Technological solutions that monitor PwD (e.g. global positioning system trackers, cameras, motion sensors, bed and fall sensors, position change alarms) were used both at home and care home facilities, usually to collect information from PwD's activities and convey it to relatives or carers. We also found carer support to be another relevant purpose of technology, albeit less frequent. $13 \%$ of the reviewed studies $(n=33)$ employed technologies to aid carers, mainly serving to provide education regarding the management of PwD (e.g. Telecare), provide emotional support networks, and facilitate the coordination of different actors involved in the care of a PwD. Finally, activity recognition is another purpose associated with the use of technology and not directly related to the NR framework. Activity recognition is a process commonly used in smart homes or other intelligent environments, whereby sensory technology recognizes what the behavior of an individual is in order to provide adequate assistive services at the opportune moment (Roy et al., 2011). Activity recognition is a key element in the development of technological solutions that can interpret PwD's behaviors and use such information to feed the user (patient or/and carer) with context-sensitive instructions. $11 \%$ (n $=27$ ) of the reviewed studies employed technology for this purpose.

It is important to note that $21 \%$ of studies $(n=53)$ considered technological solutions that combined more than one purpose. The most frequent combinations were compensationmonitoring $(n=16)$, compensation-monitoring-environment modification $(n=7)$ and compensation-environment modification $(n=6)$. The interaction of purposes often occurred in two ways. Some technologies automatically offered information to the carer after the failure of an attempted compensation (e.g. using reminders to take medicines) or environmental modification (e.g. the stove did not turn off). Other technologies offered the possibility for the PwD to ask for help when unable to perform a task on his/her own (e.g. trigger an alarm after a fall).

\subsection{Types of impairments and disabilities addressed by technology (Question 3)}

A first result regarding impairments and disabilities addressed by technology is that studies rarely classified these explicitly. As Table 2 shows, the most frequently targeted cognitive 
functions (impairments) were time and place orientation $(n=87)$, sequencing complex actions $(n=52)$, memory $(n=47)$ and communication $(n=44)$. In many cases, technological solutions were used with different purposes to support the same cognitive function. For example, regarding time and place orientation, technology was sometimes used to compensate ( $\mathrm{n}=42$, e.g. reminding a PwD that is night time so he/she stays in bed), monitor ( $\mathrm{n}=52$, e.g. informing relatives that the PwD has left the bed or bedroom), or modify the environment ( $\mathrm{n}=16$; e.g. turn on the lights when PwD leaves bed to avoid falls). A similar situation was observed in relation to memory. However, in this case technology was more frequently used as a compensatory tool $(n=40$, e.g. reminder of an appointment) compared to monitoring $(\mathrm{n}=10$, e.g. informing carers when the PwD has forgotten to take his/her medicines).

\section{Insert here Table 2}

In relation to disabilities, technological solutions aimed at compensating cognitive functions targeted a wide variety of activities of daily living (see Table 3). They were commonly used in helping PwD to scaffold the sequencing of complex actions related to leisure, cooking and bathroom routines. Technologies were also frequently employed to compensate PwD's memory impairments, so that they could keep and follow a schedule, find objects or remember to take medications. Communication and place-time orientation were other domains also commonly targeted.

insert here Table 3

Technological solutions used to modify the environment were mainly concerned with two key activities of daily living: sleeping and cooking (see Table 4). Regarding sleeping, technology aimed to decrease time orientation problems at night by turning lights on when PwD left their beds, a problem commonly known as night wandering. As for cooking, automatic stoves that turned off when a certain time elapsed or when smoke or gas were detected were commonly used to support PwD's memory impairments by decreasing the cognitive load of tasks. 
When technology was used for monitoring purposes, the main goal was to keep the PwD safe while performing different ADLs. In general, monitoring technologies identified situations where PwD experienced difficulties performing an activity, and sent that information to carers so they could offer assistance (see Table 5). More than half of the studies $(n=52)$ that used technological solutions to monitor PwD's behaviors targeted place and time orientation deficits compromising PwD's capacities to find their way both indoors and outdoors, as well as day/night sleep patterns (night wandering). Walking was another activity frequently monitored by technological solutions, particularly to reduce risks of falls related to balance problems $(n=8)$. Many technological solutions also incorporated alarms that sent information to the carer when a compensatory intervention failed (orientation in place compensations, $\mathrm{n}=6$; orientation in time compensations, $\mathrm{n}=3$; memory compensations, $\mathrm{n}=8$; balance compensations, $\mathrm{n}=3$ ).

Insert here Table 5

Finally, when technology was used to retrain cognitive functions there was no emphasis on specific ADLs. In other words, cognitive retraining did not address particular disabilities in real life activities. The common underlying assumption in these studies was that by engaging in cognitive drills PwD would improve - or maintain - cognitive abilities. A common limitation of this group of studies was that they either targeted several cognitive abilities (mass training), or did not specify the targeted impaired function (see Table 6).

Insert here Table 6

\subsection{Facilitation of engagement of PwD with technology (Question 4)}

In order to respond to this question, all studies where PwD were actively involved with technology were considered for analysis $(n=138)$. From this sub-sample, only $42 \%$ of studies ( $\mathrm{n}=58)$ accounted for PwD's engagement with technology when describing the design or application of a technological solution, with varying depth and detail. Most of these studies $(n=38)$ only mentioned one element of the design that had to be adapted or modified 
in order to facilitate PwD's engagement with technology, and only five articles considered three or more adaptations.

The variables considered by researchers in order to facilitate PwD's engagement with technology were classified as related to the technological solution and to the carer, who mediates the relationship between technology and the PwD (Table 7). In relation to variables related to technological solutions, an important number of studies $(n=32)$ suggested the need to consider the cognitive demands placed by technology and how these demands interact with the cognitive impairments commonly presented by PwD. This issue was often addressed through developing technologies that were: simple (e.g. few elements to interact with, few steps involved in the interaction and minimum intervention of $\mathrm{PwD}$ ); reliable (i.e. faulttolerant, referring to the ability of a system to continue operating in a satisfactory way even in case of malfunctioning of some of its part of erroneous/unexpected interaction with the user); intuitive (requiring a minimal amount of learning, if any at all); as well as cognitionenhancing (e.g. leveraging cognitive strengths to compensate for cognitive difficulties, such as pictorial stimuli and simple language used to facilitate attentional engagement). Some studies $(n=7)$ also referred to physical features of technological solutions as factors that could potentially influence its use. Size (not bulky), portability (easy to carry), concealability (to avoid looking different) and familiarity (to look similar to everyday life objects) were commonly considered as factors that should be accounted for in order to increase PwD's engagement with technology.

\section{Insert here Table 7}

The level of personalization of the technology was a particularly relevant design feature implemented to facilitate engagement. An important number of studies $(n=18)$ referred to this element, in terms of how much a technology fits the PwD's habitual practices and preferences, and uses personal information to tailor contents and prompts/instructions. Equally important appears to be the emotional experience that a PDD has when using a technology. Several studies $(n=11)$ mentioned this element, emphasizing that technological solutions must generate positive emotions and avoid triggering confusion and anxiety. Technologies that incorporate social characteristics (e.g. use of friendly voice to convey prompt messages) and reassure the PwD were described as useful to facilitate emotional engagement and consequently improve the emotional experience. 
The importance of the interaction between PwD and technology was often emphasized in technological solutions that were capable of monitoring the interaction in real time and use such information to provide ad-hoc responses that facilitate PwD's engagement ( $n=12$ studies). The best example here were technologies that adjust prompts based on PwD's actual performance (e.g. number of errors, cognitive and sensory status, responsiveness to previous prompts), or use prompts to regulate PwD's psychological states (e.g. confusion, inactivity, boredom, stress) thus reinforcing positive engagement.

Finally, a small number of studies $(n=5)$ stressed the importance of considering the carer as a key element in promoting PwD engagement with technology. Carers were seen as crucial for the decision-making process (e.g. determine PwD's needs and abilities to use technology, identify more suitable technological solutions, etc.). They were also seen as key to facilitate the use of technology once it was adopted (e.g. reinforce its use; seek help from professionals when there were problems, etc.).

\section{Discussion}

The main goal of this review was to explore the use of technological solutions for PwD using an NR theoretical framework. Findings showed that PwD are the main users of technological solutions in more than half of the studies (55\%). The most frequent purposes of technology use were compensation (52\%) and monitoring (33\%), commonly supporting impairments in orientation, sequencing complex actions and memory, in a wide range of basic and instrumental activities of daily living. Very few studies explicitly addressed the issue of engagement with technology. By adopting a NR approach our review generated knowledge helpful to gain a better understanding of why and how technology is employed to help PwD and their carers, addressing limitations of previous relevant reviews. In this section we will discuss the theoretical and practical implications of our findings.

\subsection{NR as a framework for the systematic analysis of dementia technologies}

A key outcome of our work was the formulation of an NR-based schema for the systematic classification of studies - and related technological solutions - based on three key dimensions: purpose of technology, impaired function and targeted activity/disability. The proposal of this NR-based schema responds to the need for theoretical frameworks to understand how technologies consider and address dementia-specific problems and limitations. Based on previous reviews in the dementia field (Marshall \& Hutchinson, 2001; Topo, 2009), it can be argued that such understanding is hindered by issues related to lack of conceptual clarity, scarcity of theory-guided research, and diversity of outcome measurements. In particular, 
Marshall and Hutchinson (2001) stress the importance of striving for methodological rigor and theoretical soundness when conducting research with an already difficult population to study. We believe that the proposed NR-based schema represents a suitable solution to address these issues (Figure 3).

Insert here figure 3

The classification of intervention approaches proposed by Mateer and Sohlberg (2003) served to categorize the purpose of technological solutions in most of the reviewed studies $(62 \%)$. Investigating technology purposes in the remaining studies then led us to extend Mateer and Sohlberg's classification with two additional types of technological purposes: carer support and monitoring. Even though carer support is not explicitly included in Mateer and Sohlberg's classification, it has been described as a key intervention in the NR of people with both acquired (Cameron \& Gignac, 2008; Evans-Roberts, Weatherhead \& Vaughan, 2014; Norup, 2018) and degenerative brain damage (Clare, 2008; Zarit \& Edwards, 2008). Concerning monitoring technologies, the NR literature appears not to have paid much explicit attention to such intervention (see later section for a discussion on this topic). Overall, the classification of purposes presented in Figure 3 allowed us to arrange all the reviewed studies based on how technological solutions were used to address specific impairments.

\subsection{Expanding the scope of technology-based interventions}

This review generated important insights regarding the current dominant scope of technology-based interventions, its implications, and how this could be improved by future research. The vast majority of the reviewed studies focused on using technological solutions to address cognitive impairments in the context of predominantly individual activities. As noted by Wilson (2005), the core goal of NR is the amelioration of emotional, cognitive, and social deficits. Accordingly, technology should address cognitive impairments as much as social and emotional issues. It is clear by the results of this review that this is not the case. Technology appears to have been strongly conceived as a form of cognitive prosthetic, thus tending to neglect social and emotional domains. Data from this review suggests that only a relatively small number of technologies were designed to support PwD's social relationships, by helping them to communicate with others who are not present (e.g. making a phone call), or scaffolding face to face social interactions (e.g. suggesting topics to include in the conversation). In relation to emotional problems, very few studies focused on managing 
negative emotions and/or promoting positive ones (e.g. soothing technologies or social pets). However, it is necessary to clarify that the exclusion of emotional and social variables, when designing and implementing assistive technologies for $\mathrm{PwD}$, is a problem that reflects a broader limitation of the field of NR itself. Only recently emotional and social dimensions have become central elements of NR theoretical models (McDonald, 2017; Bowen, Yeates \& Palmer, 2010; Wilson \& Gracey, 2009), slowly permeating the treatment of PwD (Clare, 2008). As a consequence, the operationalization of these variables, in terms of how to assess and monitor them, both in clinical and research settings, has been significantly slower compared to cognitive functions. A closer consideration of existing models in NR will help researchers to develop and test assistive technologies that can target PwD's emotional and social needs.

\subsection{Promoting an integrative approach to the analysis, design and implementation of technologies}

Key findings of this review indicate that different technological solutions can be used with different complementary purposes in order to support a given cognitive function in the context of relevant ADLs. For example, a PwD who experiences memory problems and struggles to cook a meal can be helped by a combination of: compensatory technologies (e.g. a reminder about each of the necessary steps to cook breakfast, and a prompt to turn off the stove when the meal is ready); monitoring technologies (e.g. information sent to the carer reporting that the PwD is cooking); and technologies that modify the environment (e.g. a stove with a timer that turns it off after a given amount of time). Such convergence of technologies suggests that solutions can be designed as a system in which different technological tools can synergistically contribute to the same goal, consisting in addressing a specific cognitive deficit in relation to a specific activity. The development of a system, composed by several strategies that support an impaired cognitive function, is a key theoretical principle in the holistic rehabilitation of cognitive deficits (Winson, Wilson \& Bateman, 2017).

\subsection{Conceptualizing Monitoring from an NR point of view}

As previously noted, monitoring was a highly frequent technology purpose (33\%) in the reviewed studies. However, little has been said about this type of intervention in the NR field. In general, monitoring, offers information about the state or location of the patient without feeding this information back to him/her (O’Neill \& Gillespie, 2015). It is generally agreed that monitoring allows individuals to be assisted when needed, enabling a degree of 
independence and guaranteeing the individual's safety (Riikonen, Makela \& Perala, 2010). It has also been suggested that the perceived intrusiveness of monitoring can be modulated by using technology in the context of a person-centered approach, overtly tailored to individual needs (Niemeijer et al., 2015). This implies developing and implementing monitoring technologies not just to guarantee PwD's safety, but most importantly to reduce restraints and enhance their capabilities (Niemeijer, Frederiks, Depla, Eefsting \& Herthog, 2013). This person-centered use of monitoring technologies is highly coherent with the NR framework.

\subsection{Developing a model to conceptualize PwD's engagement with technological solutions}

As noted before, engaging PwD in activities requiring the use of technological devices can be challenging, with many PwD struggling even to manage everyday technologies such as credit cards and mobile phones (Nygard \& Kottorp, 2014; Nygard \& Starkhammar, 2007).

However, there is also evidence describing a positive attitude of PwD towards technology, when adaptations are considered in order to facilitate accessibility and support engagement (Dove \& Astell, 2017). Results from this review can contribute to advancing a preliminary model of PwD's engagement with technology, based on six categories of interacting factors abstracted from the data (see Fig. 4). This model of engagement with technology should be treated as "work in progress", since further research is needed to explore and include other variables not explicitly mentioned in the reviewed studies (see implementation of safety feature in Shore, Power, de Eyto \& O’Sullivan, 2018 and contextual factors in Czaja \& Nair, 2012; Karwowski, 2012). In addition, models of PwD engagement in non-technologymediated activities could provide valuable insights to identify further factors potentially relevant to promote engagement with technology for this population. The Comprehensive Process Model of Engagement proposed by Cohen-Mansfield and collaborators (2011), for example, proposes three variables that can affect PwD's engagement with objects, activities and other people which can be incorporated in our model: environmental characteristics (e.g. level of lighting and sound in the environment); personal characteristics (e.g. demographic characteristics of the PwD; level of cognitive functioning); and stimulus attributes (e.g. real/virtual social contact; customization to individual interests and capabilities).

Insert here Figure 4

\subsection{Understanding the use of technology as a relationship}

As noted in the previous section, there is a growing body of literature interested in how PwD 
and technological solutions dynamically interact, and how this interaction influences PwD's level of engagement with technology. Among the many features that promote engagement, human-like social interaction capabilities and adaptability to the state of PwD appear to have a key role in promoting positive emotional states and reducing confusion and anxiety. Some authors have conceptualized this dynamic interaction between PwD and technology as a relationship. This idea is coherent with studies reporting that people with mild and moderate dementia can feel unconfident and confused when interacting with simple (e.g. alarm clocks, radios) and new technological objects (Bouma, 1998; Nygard \& Starkhammar, 2007). Furthermore, there is evidence suggesting that even individuals with mild-stage dementia report a higher "perceived difficulty" in using everyday technology compared to people with mild cognitive impairment or controls (Rosenberg, Kottorp, Winblad \& Nygard, 2009). In view of this data, researchers have emphasized the need to consider relational elements when developing a technological solution, or introducing one to a PwD, particularly in terms of whether and how the PwD can trust a technological solution, and feel confident that he/she is in control of it (Lindqvist, Nygard \& Borell, 2013). A related strand of literature has further developed this idea, suggesting that when interacting with PwD technology should emulate a carer, imitating the effective strategies used by the carer, attempting to empower PwD instead of taking control away from them, and encouraging PwD to resolve the problems by themselves rather than doing things for them. This approach would require technological solutions to emulate a typical three stage carer response where information is communicated to the PwD and reassurance is offered (Orpwood et al., 2005): a) provide a reminder (e.g. prompt: "don't forget you have left the tap running"), b) intervene if the user does not respond to the reminder (e.g. prompt: "turn off the tap"); c) let the user know what has been done (e.g. prompt: "your bath is ready. I have turned off the tap"). It is the opinion of the authors that future technology development should incorporate such relational approach in order to target not only cognitive impairments, but also the emotional consequences of experiencing cognitive deficits and using technology as a tool to reduce its impact on everyday life.

\section{$6 \quad$ Limitations and future directions}

In sum, and based on the results presented by this critical review, the use of a NR framework appears to bring order and theoretical coherence to a field that has seen a dramatic increase in the number of available technological solutions as well as studies exploring its usefulness in PwD. In our opinion, this framework will allow developers and researchers to 
understand the place that technologies can have in the rehabilitation of $\mathrm{PwD}$, thus, facilitating a better integration between technological and non-technological interventions. We hope this study also contributes to the field by promoting a shared language between developers, researchers and clinicians, so that comparison and replication between studies become possible. This is perhaps one of the main limitations of the field today.

There are specific limitations of this review that will need to be addressed by future studies. For example, how the level of dementia (mild-moderate-severe) interacts with the use of technological solutions. It is likely that technology plays different roles as PwD move from early to late stages. However, most studies do not consider this variable when designing technological solutions, or conceptualize the level of dementia using dissimilar categories. A related question that requires further exploration is the relationship that technological solutions can have with specific types of dementia, which tend to present particular constellations of cognitive/behavioral deficits and difficulties in ADL. Another limitation of this review is that it doesn't assess the effectiveness of diverse technological solutions. We believe that such task could be better accomplished by using the NR framework, for example, comparing the effectiveness of technologies according to its main purpose (compensation, monitoring, etc.) and the deficit/disability they target. 


\section{References}

Bharucha, A. J., Anand, V., Forlizzi, J., Dew, M. A., Reynolds III, C. F., Stevens, S., \& Wactlar, H. (2009). Intelligent assistive technology applications to dementia care: current capabilities, limitations, and future challenges. The American journal of geriatric psychiatry, 17(2), 88-104.

Bouma, H. (1998). Gerontechnology: Emerging technologies and their impact on aging in society. In J. Graafman, V. Taipale \& N. Charness (Eds.), Gerontechnology, a sustainable investment in the future. Amsterdam: IOS Press.

Bowen, C., Yeates, G., \& Palmer, S. (2010). A relational approach to rehabilitation: Thinking about relationships after brain injury. Karnac Books.

Cahill, S., Begley, E., Faulkner, J. P., \& Hagen, I. (2007). " It gives me a sense of independence"Findings from Ireland on the use and usefulness of assistive technology for people with dementia. Technology and Disability, 19(2, 3), 133-142.

Cameron, J. I., \& Gignac, M. A. (2008). "Timing It Right": A conceptual framework for addressing the support needs of family caregivers to stroke survivors from the hospital to the home. Patient education and counseling, 70(3), 305-314.

Choi, J. \& Twamley, E.W. (2013). Cognitive rehabilitation therapies for Alzheimer's disease: a review of methods to improve treatment engagement and self-efficacy. Neuropsychology Review, 23, 48-62. 10.1007/s11065-013-9227-4.

Clare, L. (2005). Rehabilitation for people with dementia. In B. Wilson (Ed.). Neuropsychological Rehabilitation, Theory and Practice. CRC Press

Clare, L. (2008). Neuropsychological Rehabilitation and People with Dementia. New York: Psychology Press.

Cohen-Mansfield, J., Marx, M. S., Freedman, L. S., Murad, H., Regier, N. G., Thein, K., \& DakheelAli, M. (2011). The comprehensive process model of engagement. The American journal of geriatric psychiatry, 19(10), 859-870.

Czaja, S. J. \& Nair, S. N. (2012). Human Factors Engineering and Systems Design. In G. Salvendy (Ed.), Handbook of Human Factors and Ergonomics (4th ed., pp. 3-37). Hoboken, NJ: Wiley.

Dove, E., \& Astell, A. J. (2017). The use of motion-based technology for people living with dementia or mild cognitive impairment: A literature review. Journal of Medical Internet Research, 19(1): e3.

Edvardsson, D., Petersson, L., Sjogren, K., Lindkvist, M., \& Sandman, P.O. (2013). Everyday activities for people with dementia in residential aged care: Associations with person-centredness and quality of life. International Journal of Older People Nursing, 9, 269-276.

Evans, J., Brown, M., Coughlan, T., Lawson, G., \& Craven, M. P. (2015). A systematic review of dementia focused assistive technology. International Conference on Human-Computer Interaction (pp. 406-417). Springer: Cham. 
Evans-Roberts, C., Weatherhead, S., \& Vaughan, F. (2014). Working with families following brain injury. Revista Chilena de Neuropsicología, 9(1), 21-30.

Fernández-Mayoralas, G., Rojo-Pérez, F., Martínez-Martín, P., Prieto-Flores, M.E., RodríguezBlázquez, C., Martín-García, S., Rojo-Abuín, J.M. \& Forjaz, M.J. (2015). Active ageing and quality of life: factors associated with participation in leisure activities among institutionalized older adults, with and without dementia. Aging \& Mental Health, 19, 1031-1041.

Georges, J., Jansen, S., Jackson, J., Meyrieux, A., Sadowska, A., \& Selmes, M. (2008). Alzheimer's disease in real life-the dementia carer's survey. International journal of geriatric psychiatry, 23(5), 546-551.

Gibson, G., Newton, L., Pritchard, G., Finch, T., Brittain, K., \& Robinson, L. (2016). The provision of assistive technology products and services for people with dementia in the United Kingdom. Dementia, 15(4), 681-701.

Karwowski, W. (2012). The Discipline of Human Factors and Ergonomics. In G. Salvendy (Ed.), Handbook of Human Factors and Ergonomics (4th ed., pp. 3-37). Hoboken, NJ: Wiley.

Kolanowski, A., \& Buettner, L. (2008). Prescribing activities that engage passive residents. An innovative method. Journal of Gerontological Nursing, 34, 13-18.

Liu, K. P. Y., Chan, C. C. H., Chu, M. M. L., Ng, T. Y. L., Chu, L. W., Hui, F. S. L., ... \& Fisher, A. G. (2007). Activities of daily living performance in dementia. Acta Neurologica Scandinavica, $116(2), 91-95$.

Lindqvist, E., Nygård, L., \& Borell, L. (2013). Significant junctures on the way towards becoming a user of assistive technology in Alzheimer's disease. Scandinavian Journal of Occupational Therapy, 20(5), 386-396.

LoPresti, E. F., Mihailidis, A., \& Kirsch, N. (2004). Assistive technology for cognitive rehabilitation: State of the art. Neuropsychological Rehabilitation, 14(1-2), 5-39.

Marshall, M. J., \& Hutchinson, S. A. (2001). A critique of research on the use of activities with persons with Alzheimer's disease: A systematic literature review. Journal of Advanced Nursing, 35(4), 488-496.

Mateer, C. A., \& Sohlberg, M. M. (2003). Cognitive rehabilitation revisited. Brain Impairment, $4(01), 17-24$.

McDonald, S. (2017). Emotions are rising: The growing field of affect neuropsychology. Journal of the International Neuropsychological Society, 23(9-10), 719-731.

Moher, D., Liberati, A., Tetzlaff, J., \& Altman, D. G. (2009). Preferred reporting items for systematic reviews and meta-analyses: the PRISMA statement. Annals of internal medicine, 151(4), 264-269.

Niemeijer, A. R., Depla, M. F., Frederiks, B. J., \& Hertogh, C. M. (2015). The experiences of people with dementia and intellectual disabilities with surveillance technologies in residential care. Nursing ethics, 22(3), 307-320. 
Niemeijer, A., Frederiks, B., Depla, M. F. I. A., Eefsting, J., \& Hertogh, C. M. P. M. (2013). The place of surveillance technology in residential care for people with intellectual disabilities: is there an ideal model of application. Journal of Intellectual Disability Research, 57(3), 201-215.

Norup, A. (2018). Family matters in neurorehabilitation: why, when, who and how. Revista Iberoamericana de Neuropsicología, 1(1), 17-31.

Nygård, L., \& Starkhammar, S. (2007). The use of everyday technology by people with dementia living alone: Mapping out the difficulties. Aging \& Mental Health, 11(2), 144-155.

Nygård, L., \& Kottorp, A. (2014). Engagement in instrumental activities of daily living, social activities, and use of everyday technology in older adults with and without cognitive impairment. British Journal of Occupational Therapy, 77(11), 565-573.

O’Neill, B \& Gillespie, A. (2015). Assistive Technologies for Cognition. A Handbook for Clinicians and Developers. Hove: Psychology Press.

Orpwood, R., Gibbs, C., Adlam, T., Faulkner, R., \& Meegahawatte, D. (2005). The design of smart homes for people with dementia-user-interface aspects. Universal Access in the information society, 4(2), 156-164.

Paillard-Borg, S., Wang, H-X, Winblad, B. \& Fratiglioni, L. (2009). Pattern of participation in leisure activities among older people in relation to their health conditions and contextual factors: a survey in a Swedish urban area. Ageing and Society, 29, 803-821.

Qiu, C. \& Fratiglioni, L. (2011). Epidemiology of Dementias. In P. McNamara (Ed.), Dementia. Volume 1: History and Incidence (pp. 1-34). Santa Barbara, California: Praeger.

Riikonen, M., Mäkelä, K., \& Perälä, S. (2010). Safety and monitoring technologies for the homes of people with dementia. Gerontechnology, 9(1), 32-45.

Rosenberg, L., Kottorp, A., Winblad, B., \& Nygård, L. (2009). Perceived difficulty in everyday technology use among older adults with or without cognitive deficits. Scandinavian journal of occupational therapy, 16(4), 216-226.

Roy, P. C., Giroux, S., Bouchard, B., Bouzouane, A., Phua, C., Tolstikov, A., \& Biswas, J. (2011). A possibilistic approach for activity recognition in smart homes for cognitive assistance to Alzheimer's patients. In Activity Recognition in Pervasive Intelligent Environments (pp. 33-58). Atlantis Press.

Shore, L., Power, V., de Eyto, A. \& O’Sullivan, L.W. (2018). Technology acceptance and usercentred design of exoskeleton for older adults: a commentary. Robotics, 7, 3.

Topo, P. (2009). Technology studies to meet the needs of people with dementia and their caregivers: a literature review. Journal of Applied Gerontology, 28(1), 5-37.

World Health Organization (1980) International Classification of Impairments, Disabilities, and Handicaps. A manual of classification relating to the consequence of disease. Geneva: World Health Organization

Wilson, B. A. (1997). Cognitive rehabilitation: How it is and how it might be. Journal of the International Neuropsychological Society, 3(05), 487-496. 
Wilson, B. A. (2005). The theory and practice of neuropsychological rehabilitation: An overview. In Wilson, B. A. (Ed.), Neuropsychological rehabilitation: Theory and practice. CRC Press.

Wilson, B. A. (2008). Neuropsychological rehabilitation. Annual Review of Clinical Psychology, $4(1), 141-162$.

Wilson, B.A. \& Gracey, F. (2009) Towards a comprehensive model of neuropsychological rehabilitation. In B. Wilson, F. Gracey, J. Evans and A. Bateman (Eds.) Neuropsychological Rehabilitation. Theory, Models, Therapy and Outcome. New York: Cambridge University Press.

Winson, R., Wilson, B. A., \& Bateman, A. (Eds.). (2017). The Brain Injury Rehabilitation Workbook. Guilford Publications.

Zarit, S. H., \& Edwards, A. B. (2008). Family caregiving: Research and clinical intervention. In R. T. Woods \& L. Clare (Eds.), Handbook of the clinical psychology of ageing (2nd ed.). (pp. 255-288). Chichester: John Wiley \& Sons Ltd. 


\section{Appendix}

Abbate, S., Avvenuti, M., \& Light, J. (2012). MIMS: A minimally invasive monitoring sensor platform. IEEE Sensors Journal, 12(3), 677-684.

Adlam, T., Faulkner, R., Orpwood, R., Jones, K., Macijauskiene, J., \& Budraitiene, A. (2004). The installation and support of internationally distributed equipment for people with dementia. IEEE Transactions on Information Technology in Biomedicine, 8(3), 253-257.

Al-Muhanna, H., Al-Wabil, R., Al-Mazrua, H., Al-Fadhel, N., \& Al-Wabil, A. (2011, July). An interactive multimedia system for monitoring the progressive decline of memory in alzheimer's patients. In International Conference on Human-Computer Interaction (pp. 381385). Springer, Berlin, Heidelberg.

Alm, N., Astell, A., Gowans, G., Dye, R., Ellis, M., Vaughan, P., \& Newell, A. F. (2007, July). An interactive entertainment system usable by elderly people with dementia. In International Conference on Universal Access in Human-Computer Interaction (pp. 617-623). Springer, Berlin, Heidelberg.

Alm, N., Astell, A., Gowans, G., Dye, R., Ellis, M., Vaughan, P., \& Riley, P. (2009, July). Lessons learned from developing cognitive support for communication, entertainment, and creativity for older people with dementia. In International Conference on Universal Access in HumanComputer Interaction (pp. 195-201). Springer, Berlin, Heidelberg.

Almudevar, A., Leibovici, A., \& Tentler, A. (2008). Home monitoring using wearable radio frequency transmitters. Artificial Intelligence in Medicine, 42(2), 109-120.

Al-Oraibi, S., Fordham, R., \& Lambert, R. (2012). Impact and economic assessment of assistive technology in care homes in Norfolk, UK. Journal of Assistive Technologies, 6(3), 192-201.

Aloulou, H., Mokhtari, M., Tiberghien, T., Biswas, J., Phua, C., Lin, J. H. K., \& Yap, P. (2013). Deployment of assistive living technology in a nursing home environment: methods and lessons learned. BMC medical informatics and decision making, 13(1), 42.

Altus, D. E., Mathews, R. M., Xaverius, P. K., Engelman, K. K., \& Nolan, B. A. (2000). Evaluating an electronic monitoring system for people who wander. American Journal of Alzheimer's Disease, 15(2), 121-125.

Alwan, M., Rajendran, P. J., Kell, S., Mack, D., Dalal, S., Wolfe, M., \& Felder, R. (2006, April). A smart and passive floor-vibration based fall detector for elderly. In Information and Communication Technologies (Vol. 1, pp. 1003-1007).

Alwin, J., Persson, J., \& Krevers, B. (2013). Perception and significance of an assistive technology intervention-the perspectives of relatives of persons with dementia. Disability and rehabilitation, 35(18), 1519-1526.

Amirjavid, F., Bouzouane, A., \& Bouchard, B. (2014). Activity modeling under uncertainty by trace of objects in smart homes. Journal of Ambient Intelligence and Humanized Computing, 5(1), 159-167.

Arntzen, C., Holthe, T., \& Jentoft, R. (2016). Tracing the successful incorporation of assistive technology into everyday life for younger people with dementia and family carers. Dementia, 15(4), 646-662.

Augusto, J., Mulvenna, M., Zheng, H., Wang, H., Martin, S., McCullagh, P., \& Wallace, J. (2014). Night optimised care technology for users needing assisted lifestyles. Behaviour \& Information Technology, 33(12), 1261-1277.

Baker, R., Dowling, Z., Wareing, L. A., Dawson, J., \& Assey, J. (1997). Snoezelen: its long-term and short-term effects on older people with dementia. British Journal of Occupational Therapy, 60(5), 213-218.

Bank, A. L., Argüelles, S., Rubert, M., Eisdorfer, C., \& Czaja, S. J. (2006). The value of telephone support groups among ethnically diverse caregivers of persons with dementia. The Gerontologist, 46(1), 134-138. 
Bankole, A., Anderson, M., Smith-Jackson, T., Knight, A., Oh, K., Brantley, J., ... \& Lach, J. (2012). Validation of noninvasive body sensor network technology in the detection of agitation in dementia. American Journal of Alzheimer's Disease \& Other Dementias ${ }^{\circledR}, 27(5), 346-354$.

Barnard, P. J., Murphy, F. C., Carthery-Goulart, M. T., Ramponi, C., \& Clare, L. (2011). Exploring the basis and boundary conditions of SenseCam-facilitated recollection. Memory, 19(7), 758767.

Baruch, J., Downs, M., Baldwin, C., \& Bruce, E. (2004). A case study in the use of technology to reassure and support a person with dementia. Dementia, 3(3), 372-377.

Beattie, M., Hallberg, J., Nugent, C., Synnes, K., Cleland, I., \& Lee, S. (2014, June). A collaborative patient-carer interface for generating home-based rules for self-management. In International Conference on Smart Homes and Health Telematics (pp. 93-102). Springer, Cham.

Beauchamp, N., Irvine, A. B., Seeley, J., \& Johnson, B. (2005). Worksite-based internet multimedia program for family caregivers of persons with dementia. The Gerontologist, 45(6), 793-801.

Becker, S. A., \& Webbe, F. (2006, November). Use of handheld technology by older adult caregivers as part of a virtual support network. In Pervasive Health Conference and Workshops, 2006(pp. 1-10). IEEE.

Becker, S. A., \& Webbe, F. M. (2008). The potential of hand-held assistive technology to improve safety for elder adults aging in place.

Begum, M., Wang, R., Huq, R., \& Mihailidis, A. (2013, June). Performance of daily activities by older adults with dementia: The role of an assistive robot. In Rehabilitation Robotics (ICORR), 2013 IEEE International Conference on (pp. 1-8). IEEE.

Beigl, M. (2000). MemoClip: A location-based remembrance appliance. Personal and Ubiquitous Computing, 4(4), 230-233.

Bemelmans, R., Gelderblom, G. J., Jonker, P., \& de Witte, L. (2015). Effectiveness of robot Paro in intramural psychogeriatric care: A multicenter quasi-experimental study. Journal of the American Medical Directors Association, 16(11), 946-950.

Bewernitz, M. W., Mann, W. C., Dasler, P., \& Belchior, P. (2009). Feasibility of machine-based prompting to assist persons with dementia. Assistive Technology, 21(4), 196-207.

Bharucha, A. J., Anand, V., Forlizzi, J., Dew, M. A., Reynolds III, C. F., Stevens, S., \& Wactlar, H. (2009). Intelligent assistive technology applications to dementia care: current capabilities, limitations, and future challenges. The American journal of geriatric psychiatry, 17(2), 88104

Bjørneby, S., Topo, P., Cahill, S., Begley, E., Jones, K., Hagen, I., ... \& Holthe, T. (2004). Ethical considerations in the ENABLE project. Dementia, 3(3), 297-312.

Boger, J., Hoey, J., Poupart, P., Boutilier, C., Fernie, G., \& Mihailidis, A. (2006). A planning system based on Markov decision processes to guide people with dementia through activities of daily living. IEEE Transactions on Information Technology in Biomedicine, 10(2), 323-333.

Boger, J., Hoey, J., Fenton, K., Craig, T., \& Mihailidis, A. (2010). Using actors to develop technologies for older adults with dementia: A pilot study.

Boger, J., Taati, B., \& Mihailidis, A. (2016). Interdisciplinary development of manual and automated product usability assessments for older adults with dementia: lessons learned. Disability and Rehabilitation: Assistive Technology, 11(7), 581-587.

Boman, I. L., Lundberg, S., Starkhammar, S., \& Nygård, L. (2014). Exploring the usability of a videophone mock-up for persons with dementia and their significant others. $B M C$ geriatrics, 14(1), 49.

Boman, I. L., Nygård, L., \& Rosenberg, L. (2014). Users' and professionals' contributions in the process of designing an easy-to-use videophone for people with dementia. Disability and Rehabilitation: Assistive Technology, 9(2), 164-172.

Bouchard, K., Bouchard, B., \& Bouzouane, A. (2014). Spatial recognition of activities for cognitive assistance: realistic scenarios using clinical data from Alzheimer's patients. Journal of 
Ambient Intelligence and Humanized Computing, 5(5), 759-774.

Bouma, H. (1998). Gerontechnology: Emerging technologies and their impact on aging in society. In J. Graafman, V. Taipale \& N. Charness (Eds.), Gerontechnology, a sustainable investment in the future. Amsterdam: IOS Press.

Bourennane, W., Charlon, Y., Bettahar, F., Campo, E., \& Esteve, D. (2013). Homecare monitoring system: a technical proposal for the safety of the elderly experimented in an Alzheimer's care unit. Irbm, 34(2), 92-100.

Bourgeois, M. S. (1990). Enhancing conversation skills in patients with Alzheimer's disease using a prosthetic memory aid. Journal of Applied Behavior Analysis, 23(1), 29-42.

Boustani, M. A., Frame, A., Munger, S., Healey, P., Westlund, J., Farlow, M., ... \& Azar, J. (2012). Connecting research discovery with care delivery in dementia: the development of the Indianapolis Discovery Network for Dementia. Clinical interventions in aging, 7, 509.

Boyd, H. C., Evans, N. M., Orpwood, R. D., \& Harris, N. D. (2017). Using simple technology to prompt multistep tasks in the home for people with dementia: An exploratory study comparing prompting formats. Dementia, 16(4), 424-442.

Brennan, P. F., \& Moore, S. M. (1994). Networks for home care support: the ComputerLink project. Caring: National Association for Home Care magazine, 13(8), 64-6.

Bressler, K., E. Redfern, R., \& Brown, M. (2011). Elimination of position-change alarms in an Alzheimer's and dementia long-term care facility. American Journal of Alzheimer's Disease \& Other Dementias ${ }^{\circledR}, 26(8), 599-605$.

Brown, G. (2005). An accelerometer based fall detector: development, experimentation, and analysis. University of California, Berkeley.

Burdea, G., Polistico, K., Krishnamoorthy, A., House, G., Rethage, D., Hundal, J., ... \& Pollack, S. (2015). Feasibility study of the BrightBrainer ${ }^{\mathrm{TM}}$ integrative cognitive rehabilitation system for elderly with dementia. Disability and Rehabilitation: Assistive Technology, 10(5), 421432.

Burgio, L., Scilley, K., Hardin, J. M., Hsu, C., \& Yancey, J. (1996). Environmental "white noise": An intervention for verbally agitated nursing home residents. The Journals of Gerontology Series B: Psychological Sciences and Social Sciences, 51(6), P364-P373.

Caffo, A. O., Hoogeveen, F., Groenendaal, M., Perilli, V. A., Damen, M., Stasolla, F., ... \& Bosco, A. (2014). Comparing two different orientation strategies for promoting indoor traveling in people with Alzheimer's disease. Research in Developmental Disabilities, 35(2), 572-580.

Cahill, S., Begley, E., Faulkner, J. P., \& Hagen, I. (2007). " It gives me a sense of independence"Findings from Ireland on the use and usefulness of assistive technology for people with dementia. Technology and Disability, 19(2, 3), 133-142.

Calleson, D. C., Sloane, P. D., \& Cohen, L. W. (2006). Effectiveness of mailing "Bathing Without a Battle" to all US nursing homes. Gerontology \& geriatrics education, 27(1), 67-79.

Camberg, L., Woods, P., Ooi, W. L., Hurley, A., Volicer, L., Ashley, J., ... \& McIntyre, K. (1999). Evaluation of simulated presence: A personalized approach to enhance well-being in persons with Alzheimer's disease. Journal of the American Geriatrics Society, 47(4), 446-452.

Cameron, J. I., \& Gignac, M. A. "Timing It Right": A conceptual framework for addressing the support needs of family caregivers to stroke survivors from the hospital to the home. Patient education and counseling, 70(3), 305-314.

Capezuti, E., Brush, B. L., Lane, S., Rabinowitz, H. U., \& Secic, M. (2009). Bed-exit alarm effectiveness. Archives of gerontology and geriatrics, 49(1), 27-31.

Casas, R., Marco, Á., Falcó, J. L., Artigas, J. I., \& Abascal, J. (2006). Ethically aware design of a location system for people with dementia. In Computers Helping People with Special Needs (pp. 777-784). Springer, Berlin, Heidelberg.

Cavallo, F., Aquilano, M., \& Arvati, M. (2015). An ambient assisted living approach in designing domiciliary services combined with innovative technologies for patients with Alzheimer's 
disease: a case study. American Journal of Alzheimer's Disease \& Other Dementias ${ }^{\circledR}, 30(1)$, 69-77.

Chan, M., Campo, E., Laval, E., \& Estève, D. (2002). Validation of a remote monitoring system for the elderly: Application to mobility measurements. Technology and Health Care, 10(5), 391399.

Chang, Y. J., Chen, C. N., Chou, L. D., \& Wang, T. Y. (2008, January). A novel indoor wayfinding system based on passive RFID for individuals with cognitive impairments. In Pervasive Computing Technologies for Healthcare, 2008. PervasiveHealth 2008. Second International Conference on (pp. 108-111).

Chang, B. L., Nitta, S., Carter, P. A., \& Markham, Y. K. (2004). Perceived helpfulness of telephone calls. Journal of Gerontological Nursing, 30(9), 14-21.

Charlon, Y., Fourty, N., Bourennane, W., \& Campo, E. (2013). Design and evaluation of a device worn for fall detection and localization: Application for the continuous monitoring of risks incurred by dependents in an Alzheimer's care unit. Expert Systems with Applications, 40(18), 7316-7330.

Chen, D., Bharucha, A. J., \& Wactlar, H. D. (2007, August). Intelligent video monitoring to improve safety of older persons. In Engineering in Medicine and Biology Society, 2007. EMBS 2007. 29th Annual International Conference of the IEEE (pp. 3814-3817). IEEE.

Chilukoti, N., Early, K., Sandhu, S., Riley-Doucet, C., \& Debnath, D. (2007, November). Assistive technology for promoting physical and mental exercise to delay progression of cognitive degeneration in patients with dementia. In Biomedical Circuits and Systems Conference, 2007. BIOCAS 2007. IEEE (pp. 235-238).

Chiu, T., Marziali, E., Colantonio, A., Carswell, A., Gruneir, M., Tang, M., \& Eysenbach, G. (2009). Internet-based caregiver support for Chinese Canadians taking care of a family member with Alzheimer disease and related dementia. Canadian Journal on Aging/La Revue canadienne du vieillissement, 28(4), 323-336.

Choi, J. \& Twamley, E.W. (2013). Cognitive rehabilitation therapies for Alzheimer's disease: a review of methods to improve treatment engagement and self-efficacy. Neuropsychology Review, 23, 48-62. 10.1007/s11065-013-9227-4.

Corchado, J. M., Bajo, J., De Paz, Y., \& Tapia, D. I. (2008). Intelligent environment for monitoring Alzheimer patients, agent technology for health care. Decision Support Systems, 44(2), 382396.

Czaja, S. J. \& Nair, S. N. (2012). Human Factors Engineering and Systems Design. In G. Salvendy (Ed.), Handbook of Human Factors and Ergonomics (4th ed., pp. 3-37). Hoboken, NJ: Wiley.

Czaja, S. J., \& Rubert, M. P. (2002). Telecommunications technology as an aid to family caregivers of persons with dementia. Psychosomatic medicine, 64(3), 469-476.

Czarnuch, S., Cohen, S., Parameswaran, V., \& Mihailidis, A. (2013). A real-world deployment of the COACH prompting system. Journal of Ambient Intelligence and Smart Environments, 5(5), 463-478.

Clare, L. (2005). Rehabilitation for people with dementia. In B. Wilson (Ed.). Neuropsychological Rehabilitation, Theory and Practice. CRC Press

Clare, L. (2008). Neuropsychological Rehabilitation and People with Dementia. New York: Psychology Press.

Cohen-Mansfield, J., Marx, M. S., Freedman, L. S., Murad, H., Regier, N. G., Thein, K., \& DakheelAli, M. (2011). The comprehensive process model of engagement. The American journal of geriatric psychiatry, 19(10), 859-870.

Cook, D. J., \& Schmitter-Edgecombe, M. (2009). Assessing the quality of activities in a smart environment. Methods of information in medicine, 48(5), 480. 
Dahl, Y., \& Holbø, K. (2012, June). Value biases of sensor-based assistive technology: case study of a GPS tracking system used in dementia care. In Proceedings of the Designing Interactive Systems Conference (pp. 572-581). ACM.

Dale, Ø. (2010, July). Usability and usefulness of GPS based localization technology used in dementia care. In International Conference on Computers for Handicapped Persons (pp. 300307). Springer, Berlin, Heidelberg.

Dang, S., Remon, N., Harris, J., Malphurs, J., Sandals, L., Cabrera, A. L., \& Nedd, N. (2008). Care coordination assisted by technology for multiethnic caregivers of persons with dementia: a pilot clinical demonstration project on caregiver burden and depression. Journal of telemedicine and telecare, 14(8), 443-447.

Dany, S., Nedd, N., Nair, S., Roos, B., Aguila, E., Portales, A., ... \& Malphurs, J. (2004, October). Utilization of TLC technology by dementia family caregivers. In GERONTOLOGIST (Vol. 44, pp. 604-604). 1275 K STREET NW SUITE 350, WASHINGTON, DC 20005-4006 USA: GERONTOLOGICAL SOCIETY AMER.

Davis, J. D., Tremont, G., Bishop, D. S., \& Fortinsky, R. H. (2011). A telephone-delivered psychosocial intervention improves dementia caregiver adjustment following nursing home placement. International Journal of Geriatric Psychiatry, 26(4), 380-387.

Dawadi, P. N., Cook, D. J., Schmitter-Edgecombe, M., \& Parsey, C. (2013). Automated assessment of cognitive health using smart home technologies. Technology and health care, 21(4), 323343.

De Leo, G., Brivio, E., \& Sautter, S. W. (2011). Supporting autobiographical memory in patients with Alzheimer's disease using smart phones. Applied neuropsychology, 18(1), 69-76.

DeVaul, R. W., Schwartz, S., \& Pentland, A. (2003). The memory glasses project. MIThril Media Lab, Oct, 28.

Dove, E., \& Astell, A. J. (2017). The use of motion-based technology for people living with dementia or mild cognitive impairment: A literature review. Journal of Medical Internet Research, 19(1): e3.

Dröes, R. M., Bentvelzen, S., Meiland, F., \& Craig, D. (2010). Dementia-related and other factors to be taken into account when developing ict support for people with dementia-lessons from field trials. In Supporting People with Dementia Using Pervasive Health Technologies (pp. 113-127). Springer, London.

Edge, D., Blackwell, A., \& Dubuc, L. (2006). The physical world as an abstract interface. Contemporary Ergonomics, 224-228.

Edvardsson, D., Petersson, L., Sjogren, K., Lindkvist, M., \& Sandman, P.O. (2013). Everyday activities for people with dementia in residential aged care: Associations with personcentredness and quality of life. International Journal of Older People Nursing, 9, 269-276.

Eisdorfer, C., Czaja, S. J., Loewenstein, D. A., Rubert, M. P., Argüelles, S., Mitrani, V. B., \& Szapocznik, J. (2003). The effect of a family therapy and technology-based intervention on caregiver depression. The Gerontologist, 43(4), 521-531.

Engström, M., Lindqvist, R., Ljunggren, B., \& Carlsson, M. (2009). Staff members' perceptions of a ICT support package in dementia care during the process of implementation. Journal of Nursing Management, 17(7), 781-789.

Evans, J., Brown, M., Coughlan, T., Lawson, G., \& Craven, M. P. (2015). A systematic review of dementia focused assistive technology. International Conference on Human-Computer Interaction (pp. 406-417). Springer: Cham.

Evans, N., Carey-Smith, B., \& Orpwood, R. (2011). Using smart technology in an enabling way: A review of using technology to support daily life for a tenant with moderate dementia. British Journal of Occupational Therapy, 74(5), 249-253.

Evans-Roberts, C., Weatherhead, S., \& Vaughan, F. (2014). Working with families following brain injury. Revista Chilena de Neuropsicología, 9(1), 21-30. 
Faucounau, V., Riguet, M., Orvoen, G., Lacombe, A., Rialle, V., Extra, J., \& Rigaud, A. S. (2009). Electronic tracking system and wandering in Alzheimer's disease: a case study. Annals of physical and rehabilitation medicine, 52(7-8), 579-587.

Feeney Mahoney, D. M., Tarlow, B., Jones, R. N., Tennstedt, S., \& Kasten, L. (2001). Factors affecting the use of a telephone-based intervention for caregivers of people with Alzheimer's disease. Journal of Telemedicine and Telecare, 7(3), 139-148.

Ferm, U., Sahlin, A., Sundin, L., \& Hartelius, L. (2010). Using Talking Mats to support communication in persons with Huntington's Disease. International journal of language \& communication disorders, 45(5), 523-536.

Fernández-Mayoralas, G., Rojo-Pérez, F., Martínez-Martín, P., Prieto-Flores, M.E., RodríguezBlázquez, C., Martín-García, S., Rojo-Abuín, J.M. \& Forjaz, M.J. (2015). Active ageing and quality of life: factors associated with participation in leisure activities among institutionalized older adults, with and without dementia. Aging \& Mental Health, 19, 10311041.

Fook, V. F. S., Tee, J. H., Yap, K. S., Wai, A. A. P., Maniyeri, J., Jit, B., \& Lee, P. H. (2007, June). Smart mote-based medical system for monitoring and handling medication among persons with dementia. In International Conference on Smart Homes and Health Telematics (pp. 5462). Springer, Berlin, Heidelberg.

Friedman, M. (1993). A wearable computer that gives context-sensitive verbal guidance to people with memory or attention impairments. Proceedings of the Rehabilitation Society of North America (RESNA), 199-201.

Gallagher-Thompson, D., Wang, P. C., Liu, W., Cheung, V., Peng, R., China, D., \& Thompson, L. W. (2010). Effectiveness of a psychoeducational skill training DVD program to reduce stress in Chinese American dementia caregivers: results of a preliminary study. Aging \& Mental Health, 14(3), 263-273.

Garland, K., Beer, E., Eppingstall, B., \& O'Connor, D. W. (2007). A comparison of two treatments of agitated behavior in nursing home residents with dementia: simulated family presence and preferred music. The American journal of geriatric psychiatry, 15(6), 514-521.

Garrido, P. C., Ruiz, I. L., \& Gómez-Nieto, M. Á. (2013). An Alert System for People Monitoring Based on Multi-Agents using Maps. J. UCS, 19(9), 1257-124.

Gayathri, K. S., Elias, S., \& Ravindran, B. (2015). Hierarchical activity recognition for dementia care using Markov Logic Network. Personal and Ubiquitous Computing, 19(2), 271-285.

Georges, J., Jansen, S., Jackson, J., Meyrieux, A., Sadowska, A., \& Selmes, M. (2008). Alzheimer's disease in real life-the dementia carer's survey. International journal of geriatric psychiatry, 23(5), 546-551.

Gietzelt, M., Feldwieser, F., Gövercin, M., Steinhagen-Thiessen, E., \& Marschollek, M. (2014). A prospective field study for sensor-based identification of fall risk in older people with dementia. Informatics for health and social care, 39(3-4), 249-261.

Gorman, P., Dayle, R., Hood, C. A., \& Rumrell, L. (2003). Effectiveness of the ISAAC cognitive prosthetic system for improving rehabilitation outcomes with neurofunctional impairment. NeuroRehabilitation, 18(1), 57-67.

Grierson, L. E., Zelek, J., \& Carnahan, H. (2009). The application of a tactile way-finding belt to facilitate navigation in older persons. Ageing International, 34(4), 203.

Grierson, L. E., Zelek, J., Lam, I., Black, S. E., \& Carnahan, H. (2011). Application of a tactile wayfinding device to facilitate navigation in persons with dementia. Assistive Technology®, 23(2), 108-115.

Hagen, I., Cahill, S., Begley, E., Macijauskiene, J., Gilliard, J., Jones, K., ... \& Duff, P. (2005). Assessment of usefulness of assistive technologies for people with dementia. Assistive technology, 348-52.

Hallberg, L., Mellgren, E., Hartelius, L., \& Ferm, U. (2013). Talking Mats in a discussion group for 
people with Huntington's disease. Disability and Rehabilitation: Assistive Technology, 8(1), 67-76.

Hamada, T., Kuwahara, N., Morimoto, K., Yasuda, K., Akira, U., \& Abe, S. (2009, July). Preliminary study on remote assistance for people with dementia at home by using multimedia contents. In International Conference on Universal Access in Human-Computer Interaction (pp. 236-244). Springer, Berlin, Heidelberg.

Hanson, E. J., \& Clarke, A. (2000). The role of telematics in assisting family carers and frail older people at home. Health \& social care in the community, 8(2), 129-137.

Hanson, E., Magnusson, L., Arvidsson, H., Claesson, A., Keady, J., \& Nolan, M. (2007). Working together with persons with early stage dementia and their family members to design a userfriendly technology-based support service. Dementia, 6(3), 411-434.

Hardy, S., Reuter, C., Göbel, S., Steinmetz, R., Baller, G., Kalbe, E., ... \& Fathi, M. (2015). NeuroCare-Personalization and Adaptation of Digital Training Programs for Mild Cognitive Impairments. In Ambient Assisted Living (pp. 53-63). Springer, Cham.

Haritou, M., Glickman, Y., Androulidakis, A., Xefteris, S., Anastasiou, A., Baboshin, A., ... \& Koutsouris, D. (2012). A technology platform for a novel home care delivery service to patients with dementia. Journal of Medical Imaging and Health Informatics, 2(1), 49-55.

Hartin, P. J., Nugent, C. D., McClean, S. I., Cleland, I., Norton, M. C., Sanders, C., \& Tschanz, J. T. (2014, August). A smartphone application to evaluate technology adoption and usage in persons with dementia. In Engineering in Medicine and Biology Society (EMBC), 2014 36th Annual International Conference of the IEEE (pp. 5389-5392).

Hoey, J., Poupart, P., von Bertoldi, A., Craig, T., Boutilier, C., \& Mihailidis, A. (2010). Automated handwashing assistance for persons with dementia using video and a partially observable Markov decision process. Computer Vision and Image Understanding, 114(5), 503-519.

Holmes, D., Teresi, J. A., Ramirez, M., Ellis, J., Eimicke, J., Kong, J., ... \& Silver, S. (2007). An evaluation of a monitoring system intervention: falls, injuries, and affect in nursing homes. Clinical nursing research, 16(4), 317-335.

Hristoforou, E., \& Reilly, R. E. (1994). Displacement sensors using soft magnetostrictive alloys. IEEE transactions on magnetics, 30(5), 2728-2733.

Huang, H. H., Matsushita, H., Kawagoe, K., Sakai, Y., Nonaka, Y., Nakano, Y., \& Yasuda, K. (2012, August). Toward a memory assistant companion for the individuals with mild memory impairment. In Cognitive Informatics \& Cognitive Computing (ICCI* CC), 2012 IEEE 11th International Conference on (pp. 295-299). IEEE.

Hussain, M., Ali, T., Khan, W. A., Afzal, M., Lee, S., \& Latif, K. (2015). Recommendations service for chronic disease patient in multimodel sensors home environment. Telemedicine and $e-$ Health, 21(3), 185-199.

Hyry, J., Yamamoto, G., \& Pulli, P. (2011, October). Requirements guideline of assistive technology for people suffering from dementia. In Proceedings of the 4th International Symposium on Applied Sciences in Biomedical and Communication Technologies (p. 39). ACM.

Imbeault, H., Bier, N., Pigot, H., Gagnon, L., Marcotte, N., Fulop, T., \& Giroux, S. (2014). Electronic organiser and Alzheimer's disease: Fact or fiction?. Neuropsychological rehabilitation, 24(1), 71-100.

Inoue, T., Nihei, M., Narita, T., Onoda, M., Ishiwata, R., Mamiya, I., ... \& Kamata, M. (2012). Fieldbased development of an information support robot for persons with dementia. Technology and Disability, 24(4), 263-271.

Jentoft, R., Holthe, T., \& Arntzen, C. (2014). The use of assistive technology in the everyday lives of young people living with dementia and their caregivers. Can a simple remote control make a difference?. International psychogeriatrics, 26(12), 2011-2021.

Johansson, L. N. M. (2001). The experience and management of temporality in five cases of dementia. Scandinavian journal of occupational therapy, 8(2), 85-95. 
Karlsson, E., Axelsson, K., Zingmark, K., \& Sävenstedt, S. (2011). The challenge of coming to terms with the use of a new digital assistive device: a case study of two persons with mild dementia. The open nursing journal, 5, 102.

Karwowski, W. (2012). The Discipline of Human Factors and Ergonomics. In G. Salvendy (Ed.), Handbook of Human Factors and Ergonomics (4th ed., pp. 3-37). Hoboken, NJ: Wiley.

Kéri, S. (2015). How assistive technology changes the brain: the critical role of hippocampal-striatal interactions during cognitive training. Studies in health technology and informatics, 217, 601604.

Kerkhof, Y. J., Rabiee, F., \& Willems, C. G. (2015). Experiences of using a memory aid to structure and support daily activities in a small-scale group accommodation for people with dementia. Dementia, 14(5), 633-649.

Kerssens, C., Kumar, R., Adams, A. E., Knott, C. C., Matalenas, L., Sanford, J. A., \& Rogers, W. A. (2015). Personalized technology to support older adults with and without cognitive impairment living at home. American Journal of Alzheimer's Disease \& Other Dementias ${ }^{\circledR}, 30(1), 85-97$.

Khattak, A. M., Truc, P. T. H., Hung, L. X., Dang, V. H., Guan, D., Pervez, Z., ... \& Lee, Y. K. (2011). Towards smart homes using low level sensory data. Sensors, 11(12), 11581-11604.

Khosla, R., Nguyen, K., \& Chu, M. T. (2014, November). Assistive robot enabled service architecture to support home-based dementia care. In Service-Oriented Computing and Applications (SOCA), 2014 IEEE 7th International Conference on (pp. 73-80).

Kikhia, B., Hallberg, J., \& Synnes, K. (2009). Context-aware life-logging for persons with mild dementia. In Annual international conference of the IEEE Engineering in Medicine and Biology Society: 02/09/2009-06/09/2009 (pp. 6183-6186). IEEE Communications Society.

Kinney, J. M., Kart, C. S., Murdoch, L. D., \& Conley, C. J. (2004). Striving to provide safety assistance for families of elders: The SAFE house project. Dementia, 3(3), 351-370.

Kolanowski, A., \& Buettner, L. (2008). Prescribing activities that engage passive residents. An innovative method. Journal of Gerontological Nursing, 34, 13-18.

König, A., Crispim-Junior, C. F., Covella, A. G. U., Bremond, F., Derreumaux, A., Bensadoun, G., ... \& Robert, P. (2015). Ecological assessment of autonomy in instrumental activities of daily living in dementia patients by the means of an automatic video monitoring system. Frontiers in aging neuroscience, 7, 98.

Labelle, K. L., \& Mihailidis, A. (2006). The use of automated prompting to facilitate handwashing in persons with dementia. American Journal of Occupational Therapy, 60(4), 442-450.

Lancioni, G. E., Bosco, A., De Caro, M. F., Singh, N. N., O’Reilly, M. F., Green, V. A., ... \& Denitto, F. (2015). Effects of response-related music stimulation versus general music stimulation on positive participation of patients with Alzheimer's disease. Developmental neurorehabilitation, 18(3), 169-176.

Lancioni, G. E., Pinto, K., La Martire, M. L., Tota, A., Rigante, V., Tatulli, E., ... \& Sigafoos, J. (2009). Helping persons with mild or moderate Alzheimer's disease recapture basic daily activities through the use of an instruction strategy. Disability and rehabilitation, 31(3), 211219.

Lancioni, G. E., Perilli, V., O’Reilly, M. F., Singh, N. N., Sigafoos, J., Bosco, A., ... \& Groeneweg, J. (2013). Technology-based orientation programs to support indoor travel by persons with moderate Alzheimer's disease: impact assessment and social validation. Research in developmental disabilities, 34(1), 286-293.

Lancioni, G. E., Perilli, V., Singh, N. N., O’Reilly, M. F., Sigafoos, J., Bosco, A., ... \& Minervini, M. (2011). Persons with mild or moderate Alzheimer's disease use a basic orientation technology to travel to different rooms within a day center. Research in Developmental Disabilities, 32(5), 1895-1901.

Lancioni, G. E., Singh, N. N., O’Reilly, M. F., Sigafoos, J., Cassano, G., Pinto, K., ... \& Oliva, D. 
(2012). Technology-aided pictorial cues to support the performance of daily activities by persons with moderate Alzheimer's disease. Research in Developmental Disabilities, 33(1), 265-273.

Lancioni, G. E., Singh, N. N., O’Reilly, M. F., Sigafoos, J., D’Amico, F., Ferlisi, G., ... \& Belardinelli, M. O. (2015). Patients with moderate Alzheimer's disease engage in verbal reminiscence with the support of a computer-aided program: a pilot study. Frontiers in aging neuroscience, 7, 109.

Lancioni, G. E., Singh, N. N., O’Reilly, M. F., Sigafoos, J., D’Amico, F., Sasanelli, G., ... \& Signorino, M. (2015). Persons with Alzheimer's disease engage in leisure and mild physical activity with the support of technology-aided programs. Research in developmental disabilities, 37, 55-63.

Lancioni, G. E., Singh, N. N., O’Reilly, M. F., Sigafoos, J., Ferlisi, G., Zullo, V., ... \& Denitto, F. (2014). A computer-aided program for helping patients with moderate Alzheimer's disease engage in verbal reminiscence. Research in Developmental Disabilities, 35(11), 3026-3033

Lancioni, G. E., Singh, N. N., O’Reilly, M. F., Sigafoos, J., Renna, C., Pinto, K., ... \& Stasolla, F. (2014). Persons with moderate Alzheimer's disease use simple technology aids to manage daily activities and leisure occupation. Research in developmental disabilities, 35(9), 21172128.

Lancioni, G. E., Singh, N. N., O’Reilly, M. F., Sigafoos, J., Renna, C., Ventrella, M., ... \& Groeneweg, J. (2013). Supporting daily activities and indoor travel of persons with moderate Alzheimer's disease through standard technology resources. Research in developmental disabilities, 34(8), 2351-2359.

Lancioni, G. E., Singh, N. N., O’Reilly, M. F., Sigafoos, J., Tatulli, E., Rigante, V., ... \& Minervini, M. G. (2010). Technology-aided verbal instructions to help persons with mild or moderate Alzheimer's disease perform daily activities. Research in Developmental Disabilities, 31(6), 1240-1250.

Lancioni, G., Singh, N., O’Reilly, M., Zonno, N., Cassano, G., De Vanna, F., ... \& Minervini, M. (2010). Persons with Alzheimer's disease perform daily activities using verbal-instruction technology: A maintenance assessment. Developmental Neurorehabilitation, 13(2), 103-113.

Lancioni, G., Singh, N., O’Reilly, M., Zonno, N., Flora, A., Cassano, G., ... \& Minervini, M. (2009). Persons with mild and moderate Alzheimer's disease use verbal-instruction technology to manage daily activities: Effects on performance and mood. Developmental Neurorehabilitation, 12(4), 181-190.

Landau, R., \& Werner, S. (2012). Ethical aspects of using GPS for tracking people with dementia: recommendations for practice. International Psychogeriatrics, 24(3), 358-366.

Lanza, C., Knörzer, O., Weber, M., \& Riepe, M. W. (2014). Autonomous spatial orientation in patients with mild to moderate Alzheimer's disease by using mobile assistive devices: a pilot study. Journal of Alzheimer's Disease, 42(3), 879-884.

Lee, T., \& Mihailidis, A. (2005). An intelligent emergency response system: preliminary development and testing of automated fall detection. Journal of telemedicine and telecare, 11(4), 194-198.

Leuty, V., Boger, J., Young, L., Hoey, J., \& Mihailidis, A. (2013). Engaging older adults with dementia in creative occupations using artificially intelligent assistive technology. Assistive Technology, 25(2), 72-79.

Levinson, R. (1997). The planning and execution assistant and training system. J. Head Trauma Rehabil., 12(2), 769-775.

Lin, C. C., Chiu, M. J., Hsiao, C. C., Lee, R. G., \& Tsai, Y. S. (2006). Wireless health care service system for elderly with dementia. IEEE Transactions on Information Technology in Biomedicine, 10(4), 696-704.

Lin, C. C., Lin, P. Y., Lu, P. K., Hsieh, G. Y., Lee, W. L., \& Lee, R. G. (2008). A healthcare 
integration system for disease assessment and safety monitoring of dementia patients. IEEE Transactions on Information Technology in Biomedicine, 12(5), 579-586.

Liu, K. P. Y., Chan, C. C. H., Chu, M. M. L., Ng, T. Y. L., Chu, L. W., Hui, F. S. L., ... \& Fisher, A. G. (2007). Activities of daily living performance in dementia. Acta Neurologica Scandinavica, 116(2), 91-95.

Lindqvist, E., Nygård, L., \& Borell, L. (2013). Significant junctures on the way towards becoming a user of assistive technology in Alzheimer's disease. Scandinavian Journal of Occupational Therapy, 20(5), 386-396.

Lotfi, A., Langensiepen, C., Mahmoud, S. M., \& Akhlaghinia, M. J. (2012). Smart homes for the elderly dementia sufferers: identification and prediction of abnormal behaviour. Journal of ambient intelligence and humanized computing, 3(3), 205-218.

LoPresti, E. F., Mihailidis, A., \& Kirsch, N. (2004). Assistive technology for cognitive rehabilitation: State of the art. Neuropsychological Rehabilitation, 14(1-2), 5-39.

Lucero, M., Kijek, J., Malone, L., Santos, R., \& Hendrix, K. (2000). Products for Alzheimer's patients with" null" behavior. American Journal of Alzheimer's Disease, 15(6), 347-356.

Lukowicz, P., Junker, H., Stäger, M., von Bueren, T., \& Tröster, G. (2002, September). WearNET: A distributed multi-sensor system for context aware wearables. In International Conference on Ubiquitous Computing (pp. 361-370). Springer, Berlin, Heidelberg.

Lundberg, S. (2014). The results from a two-year case study of an information and communication technology support system for family caregivers. Disability and Rehabilitation: Assistive Technology, 9(4), 353-358.

Mahoney, D. F., Burleson, W., Lozano, C., Ravishankar, V., \& Mahoney, E. L. (2015). Prototype Development of a Responsive Emotive Sensing System (DRESS) to aid older persons with dementia to dress independently. Gerontechnology: international journal on the fundamental aspects of technology to serve the ageing society, 13(3), 345-358.

Mahoney, D. F., Tarlow, B. J., \& Jones, R. N. (2003). Effects of an automated telephone support system on caregiver burden and anxiety: findings from the REACH for TLC intervention study. The Gerontologist, 43(4), 556-567.

Martin, S., Augusto, J. C., McCullagh, P., Carswell, W., Zheng, H., Wang, H., ... \& Mulvenna, M. (2013). Participatory research to design a novel telehealth system to support the night-time needs of people with dementia: NOCTURNAL. International journal of environmental research and public health, 10(12), 6764-6782.

Marziali, E., Damianakis, T., \& Donahue, P. (2006). Internet-based clinical services: virtual support groups for family caregivers. Journal of Technology in Human Services, 24(2-3), 39-54.

Mateer, C. A., \& Sohlberg, M. M. (2003). Cognitive rehabilitation revisited. Brain Impairment, 4(01), 17-24.

Matthews, J. T., Lingler, J. H., Campbell, G. B., Hunsaker, A. E., Hu, L., Pires, B. R., ... \& Schulz, R. (2015). Usability of a wearable camera system for dementia family caregivers. Journal of healthcare engineering, 6(2), 213-238.

McConatha, D., McConatha, J. T., \& Dermigny, R. (1994). The use of interactive computer services to enhance the quality of life for long-term care residents. The Gerontologist, 34(4), 553-556.

McCullagh, P. J., Carswell, W., Augusto, J. C., Martin, S., Mulvenna, M. D., Zheng, H., ... \& Jeffers, W. P. (2009). State of the art on night-time care of people with dementia.

McKenzie, B., Bowen, M. E., Keys, K., \& Bulat, T. (2013). Safe home program: a suite of technologies to support extended home care of persons with dementia. American Journal of Alzheimer's Disease \& Other Dementias ${ }^{\circledR}, 28(4), 348-354$.

McShane, R., Gedling, K., Kenward, B., Kenward, R., Hope, T., \& Jacoby, R. (1998). The feasibility of electronic tracking devices in dementia: a telephone survey and case series. International journal of geriatric psychiatry, 13(8), 556-563.

Megalingam, R. K., Pocklassery, G., Jayakrishnan, V., Mourya, G., \& Thulasi, A. A. (2014, April). 
Smartphone based continuous monitoring system for home-bound elders and patients.

In Communications and Signal Processing (ICCSP), 2014 International Conference on (pp. 1173-1177). IEEE.

Meiland, F. J., Bouman, A. I., Sävenstedt, S., Bentvelzen, S., Davies, R. J., Mulvenna, M. D., ... \& Dröes, R. M. (2012). Usability of a new electronic assistive device for community-dwelling persons with mild dementia. Aging \& mental health, 16(5), 584-591.

Meiland, F. J. M., Hattink, B. J. J., Overmars-Marx, T., De Boer, M. E., Jedlitschka, A., Ebben, P. W. G., ... \& Dröes, R. M. (2014). Participation of end users in the design of assistive technology for people with mild to severe cognitive problems; the European Rosetta project. International psychogeriatrics, 26(5), 769-779.

Meza-Kubo, V., Gonzalez-Fraga, A., Morán, A. L., \& Tentori, M. (2009, November). Augmenting cognitive stimulation activities in a nursing home through pervasive computing. In Web Congress, 2009. LA-WEB'09. Latin American (pp. 8-15).

Mihailidis, A., Barbenel, J. C., \& Fernie, G. (2004). The efficacy of an intelligent cognitive orthosis to facilitate handwashing by persons with moderate to severe dementia. Neuropsychological Rehabilitation, 14(1-2), 135-171.

Mihailidis, A., Boger, J. N., Craig, T., \& Hoey, J. (2008). The COACH prompting system to assist older adults with dementia through handwashing: An efficacy study. BMC geriatrics, $8(1)$, 28.

Mihailidis, A., Blunsden, S., Boger, J., Richards, B., Zutis, K., Young, L., \& Hoey, J. (2010). Towards the development of a technology for art therapy and dementia: Definition of needs and design constraints. The Arts in Psychotherapy, 37(4), 293-300.

Mihailidis, A., Fernie, G. R., \& Barbenel, J. C. (2001). The use of artificial intelligence in the design of an intelligent cognitive orthosis for people with dementia. Assistive Technology, 13(1), 23 39.

Milne, H., van der Pol, M., McCloughan, L., Hanley, J., Mead, G., Starr, J., ... \& McKinstry, B. (2014). The use of global positional satellite location in dementia: a feasibility study for a randomised controlled trial. BMC psychiatry, 14(1), 160.

Miskelly, F. (2005). Electronic tracking of patients with dementia and wandering using mobile phone technology. Age and ageing, 34(5), 497-499.

Mokhtari, M., Aloulou, H., Tiberghien, T., Biswas, J., Racoceanu, D., \& Yap, P. (2012). New trends to support independence in persons with mild dementia-a mini-review. Gerontology, 58(6), 554-563.

Morris, A., Donamukkala, R., Kapuria, A., Steinfeld, A., Matthews, J. T., Dunbar-Jacob, J., \& Thrun, S. (2003, September). A robotic walker that provides guidance. In Robotics and Automation, 2003. Proceedings. ICRA'03. IEEE International Conference on (Vol. 1, pp. 2530). IEEE.

Moutacalli, M. T., Bouzouane, A., \& Bouchard, B. (2015). The behavioral profiling based on times series forecasting for smart homes assistance. Journal of Ambient Intelligence and Humanized Computing, 6(5), 647-659.

Mulvenna, M., Doyle, L., Wright, T., Zheng, H., Topping, P., Boyle, K., \& Martin, S. (2011). Evaluation of card-based versus device-based reminiscing using photographic images. Journal of CyberTherapy \& Rehabilitation, 4(1), 57-66.

Mulvenna, M., Martin, S., Sävenstedt, S., Bengtsson, J., Meiland, F., Dröes, R. M., ... \& Craig, D. (2010, August). Designing \& evaluating a cognitive prosthetic for people with mild dementia. In Proceedings of the 28th Annual European Conference on Cognitive Ergonomics (pp. 1118). ACM.

Murphy, J., Gray, C. M., van Achterberg, T., Wyke, S., \& Cox, S. (2010). The effectiveness of the Talking Mats framework in helping people with dementia to express their views on wellbeing. Dementia, 9(4), 454-472. 
Murphy, J., \& Oliver, T. (2013). The use of Talking Mats to support people with dementia and their carers to make decisions together. Health \& social care in the community, 21(2), 171-180.

Naeem, U., \& Bigham, J. (2009). Activity recognition in the home using a hierarchal framework with object usage data. Journal of Ambient Intelligence and Smart Environments, 1(4), 335350.

Niemeijer, A. R., Depla, M., Frederiks, B., Francke, A. L., \& Hertogh, C. (2014). CE: Original Research The Use of Surveillance Technology in Residential Facilities for People with Dementia or Intellectual Disabilities A Study Among Nurses and Support Staff. AJN The American Journal of Nursing, 114(12), 28-37.

Niemeijer, A. R., Depla, M. F., Frederiks, B. J., \& Hertogh, C. M. (2015). The experiences of people with dementia and intellectual disabilities with surveillance technologies in residential care. Nursing ethics, 22(3), 307-320.

Niemeijer, A. R., Frederiks, B. J., Riphagen, I. I., Legemaate, J., Eefsting, J. A., \& Hertogh, C. M. (2010). Ethical and practical concerns of surveillance technologies in residential care for people with dementia or intellectual disabilities: an overview of the literature. International Psychogeriatrics, 22(7), 1129-1142.

Niemeijer, A., Frederiks, B., Depla, M. F. I. A., Eefsting, J., \& Hertogh, C. M. P. M. (2013). The place of surveillance technology in residential care for people with intellectual disabilities: is there an ideal model of application. Journal of Intellectual Disability Research, 57(3), 201215.

Nijhof, N., van Gemert-Pijnen, J. E., de Jong, G. E. N., Ankoné, J. W., \& Seydel, E. R. (2012). How assistive technology can support dementia care: a study about the effects of the IST Vivago watch on patients' sleeping behavior and the care delivery process in a nursing home. Technology and disability, 24(2), 103-115.

Nijhof, N., van Gemert-Pijnen, J. E., \& Seydel, E. R. (2013). A personal assistant for dementia to stay at home safe at reduced cost. Gerontechnology, 11(3), 469-479.

Nijhof, N., van Gemert-Pijnen, L. J., Woolrych, R., \& Sixsmith, A. (2013). An evaluation of preventive sensor technology for dementia care. Journal of telemedicine and telecare, 19(2), 95-100.

Norup, A. (2018). Family matters in neurorehabilitation: why, when, who and how. Revista Iberoamericana de Neuropsicología, 1(1), 17-31.

Nugent, C., Moelaert, F., Davies, R., Donnelly, M., Savenstedt, S., Meiland, F., ... \& Bengstsson, J. E. (2008, June). Evaluation of mobile and home based cognitive prosthetics. In International Conference on Smart Homes and Health Telematics (pp. 18-25). Springer, Berlin, Heidelberg.

Nugent, C., Mulvenna, M., Moelaert, F., Bergvall-Kåreborn, B., Meiland, F., Craig, D., ... \& Dröes, R. M. (2007, June). Home based assistive technologies for people with mild dementia. In International Conference on Smart Homes and Health Telematics (pp. 63-69). Springer, Berlin, Heidelberg.

Nugent, C., O’Neill, S., Donnelly, M., Parente, G., Beattie, M., McClean, S., ... \& Craig, D. (2011, June). Evaluation of video reminding technology for persons with dementia. In International Conference on Smart Homes and Health Telematics (pp. 153-160). Springer, Berlin, Heidelberg.

Nygård, L., \& Starkhammar, S. (2007). The use of everyday technology by people with dementia living alone: Mapping out the difficulties. Aging \& Mental Health, 11(2), 144-155.

Nygård, L., Starkhammar, S., \& Lilja, M. (2008). The provision of stove timers to individuals with cognitive impairment. Scandinavian journal of occupational therapy, 15(1), 4-12.

Nygård, L., \& Kottorp, A. (2014). Engagement in instrumental activities of daily living, social activities, and use of everyday technology in older adults with and without cognitive impairment. British Journal of Occupational Therapy, 77(11), 565-573. 
de Oliveira Assis, L., Tirado, M. G. A., de Melo Pertence, A. E., Pereira, L. S. M., \& Mancini, M. C. (2010). Evaluation of cognitive technologies in geriatric rehabilitation: a case study pilot project. Occupational therapy international, 17(2), 53-63.

Olsson, A., Engström, M., Åsenlöf, P., Skovdahl, K., \& Lampic, C. (2015). Effects of tracking technology on daily life of persons with dementia: three experimental single-case studies. American Journal of Alzheimer's Disease \& Other Dementias ${ }^{\circledR}, 30(1), 29-40$.

Olsson, A., Engström, M., Lampic, C., \& Skovdahl, K. (2013). A passive positioning alarm used by persons with dementia and their spouses-a qualitative intervention study. $B M C$ geriatrics, 13(1), 11.

O’Neill, B \& Gillespie, A. (2015). Assistive Technologies for Cognition. A Handbook for Clinicians and Developers. Hove: Psychology Press.

O'Neill, S. A., Parente, G., Donnelly, M. P., Nugent, C. D., Beattie, M. P., McClean, S. I., ... \& Craig, D. (2011, August). Assessing task compliance following mobile phone-based video reminders. In Engineering in Medicine and Biology Society, EMBC, 2011 annual international conference of the IEEE (pp. 5295-5298). IEEE.

Orpwood, R., Bjørneby, S., Hagen, I., Mäki, O., Faulkner, R., \& Topo, P. (2004). User involvement in dementia product development. Dementia, 3(3), 263-279.

Orpwood, R., Chadd, J., Howcroft, D., Sixsmith, A., Torrington, J., Gibson, G., \& Chalfont, G. (2010). Designing technology to improve quality of life for people with dementia: user-led approaches. Universal Access in the Information Society, 9(3), 249-259.

Orpwood, R., Gibbs, C., Adlam, T., Faulkner, R., \& Meegahawatte, D. (2005). The design of smart homes for people with dementia - user-interface aspects. Universal Access in the information society, 4(2), 156-164.

Orpwood, R., Sixsmith, A., Torrington, J., Chadd, J., Gibson, G., \& Chalfont, G. (2007). Designing technology to support quality of life of people with dementia. Technology and Disability, 19(2, 3), 103-112.

van Osch, M., Rövekamp, A., Bergman-Agteres, S. N., Wijsman, L. W., Ooms, S. J., Mooijaart, S. P., \& Vermeulen, J. User preferences and usability of iVitality: optimizing an innovative online research platform for home-based health monitoring. Patient Prefer Adherence. 2015; 9: 857-67. doi: 10.2147/PPA. S82510.

Paillard-Borg, S., Wang, H-X, Winblad, B. \& Fratiglioni, L. (2009). Pattern of participation in leisure activities among older people in relation to their health conditions and contextual factors: a survey in a Swedish urban area. Ageing and Society, 29, 803-821.

Patterson, D. J., Etzioni, O., Fox, D., \& Kautz, H. (2002, September). Intelligent ubiquitous computing to support Alzheimer's patients: Enabling the cognitively disabled. In Adjunct Proceedings (p. 21).

Patterson, D. J., Liao, L., Fox, D., \& Kautz, H. (2003, October). Inferring high-level behavior from low-level sensors. In International Conference on Ubiquitous Computing (pp. 73-89). Springer, Berlin, Heidelberg.

Paul, Ann O. Johnson, G., \& Marnie Cranston, L. (2000). A successful videoconference satellite program: providing nutritional information on dementia to rural caregivers. Educational Gerontology, 26(5), 415-425.

Pederson, T., \& Surie, D. (2007, November). Towards an activity-aware wearable computing platform based on an egocentric interaction model. In International Symposium on Ubiquitious Computing Systems (pp. 211-227). Springer, Berlin, Heidelberg.

Perilli, V., Lancioni, G. E., Laporta, D., Paparella, A., Caffo, A. O., Singh, N. N., ... \& Oliva, D. (2013). A computer-aided telephone system to enable five persons with Alzheimer's disease to make phone calls independently. Research in developmental disabilities, 34(6), 1991-1997.

Perilli, V., Lancioni, G. E., Singh, N. N., O’Reilly, M. F., Sigafoos, J., Cassano, G., ... \& Oliva, D. (2012). Persons with Alzheimer's disease make phone calls independently using a computer- 
aided telephone system. Research in developmental disabilities, 33(4), 1014-1020.

Pfadenhauer, M., \& Dukat, C. (2015). Robot caregiver or robot-supported caregiving?. International Journal of Social Robotics, 7(3), 393-406.

Philipose, M., Fishkin, K. P., Perkowitz, M., Patterson, D. J., Fox, D., Kautz, H., \& Hahnel, D.

(2004). Inferring activities from interactions with objects. IEEE pervasive computing, 3(4), 50-57.

Pollack, M. E., Brown, L., Colbry, D., McCarthy, C. E., Orosz, C., Peintner, B., ... \& Tsamardinos, I. (2003). Autominder: An intelligent cognitive orthotic system for people with memory impairment. Robotics and Autonomous Systems, 44(3-4), 273-282.

Pot, A. M., Willemse, B. M., \& Horjus, S. (2012). A pilot study on the use of tracking technology: feasibility, acceptability, and benefits for people in early stages of dementia and their informal caregivers. Aging \& mental health, 16(1), 127-134.

Priplata, A. A., Niemi, J. B., Harry, J. D., Lipsitz, L. A., \& Collins, J. J. (2003). Vibrating insoles and balance control in elderly people. The Lancet, 362(9390), 1123-1124.

Purves, B. A., Phinney, A., Hulko, W., Puurveen, G., \& Astell, A. J. (2015). Developing CIRCA-BC and exploring the role of the computer as a third participant in conversation. American Journal of Alzheimer's Disease \& Other Dementias ${ }^{\circledR}, 30(1), 101-107$.

Rahimi, M., \& Vaughn-Cooke, M. (2007). Information architecture for an Alzheimer's communication monitoring system (ACMS). Library Subscriptions.

Riikonen, M., Mäkelä, K., \& Perälä, S. (2010). Safety and monitoring technologies for the homes of people with dementia. Gerontechnology, 9(1), 32-45.

Rodriguez-Rodriguez, A., Martel-Monagas, L., \& Lopez-Rodriguez, A. (2010). Enhancing the communication flow between Alzheimer patients, caregivers, and neuropsychologists. In Advances in Computational Biology (pp. 601-607). Springer, New York, NY.

Robinson, L., Brittain, K., Lindsay, S., Jackson, D., \& Olivier, P. (2009). Keeping In Touch Everyday (KITE) project: developing assistive technologies with people with dementia and their carers to promote independence. International Psychogeriatrics, 21(3), 494-502.

Romdhane, R., Mulin, E., Derreumeaux, A., Zouba, N., Piano, J., Lee, L., ... \& Bremond, F. (2012). Automatic video monitoring system for assessment of Alzheimer's disease symptoms. The journal of nutrition, health \& aging, 16(3), 213-218.

Rosenberg, L., \& Nygård, L. (2012). Persons with dementia become users of assistive technology: a study of the process. Dementia, 11(2), 135-154.

Rowe, M. (1999). Intervening to prevent nighttime injuries in cognitively-impaired persons living at home: A case report. Internet Journal of Advanced Nursing Practice, 3(2).

Rowe, M. A., Kelly, A., Horne, C., Lane, S., Campbell, J., Lehman, B., ... \& Benito, A. P. (2009). Reducing dangerous nighttime events in persons with dementia by using a nighttime monitoring system. Alzheimer's \& dementia, 5(5), 419-426.

Rowe, M., Lane, S., \& Phipps, C. (2007). CareWatch: a home monitoring system for use in homes of persons with cognitive impairment. Topics in geriatric rehabilitation, 23(1), 3.

Roy, P. C., Giroux, S., Bouchard, B., Bouzouane, A., Phua, C., Tolstikov, A., \& Biswas, J. (2011). A possibilistic approach for activity recognition in smart homes for cognitive assistance to Alzheimer's patients. In Activity Recognition in Pervasive Intelligent Environments (pp. 3358). Atlantis Press.

Rudzicz, F., Wang, R., Begum, M., \& Mihailidis, A. (2015). Speech interaction with personal assistive robots supporting aging at home for individuals with Alzheimer's disease. ACM Transactions on Accessible Computing (TACCESS), 7(2), 6.

Sacco, G., Joumier, V., Darmon, N., Dechamps, A., Derreumaux, A., Lee, J. H., ... \& David, R. (2012). Detection of activities of daily living impairment in Alzheimer's disease and mild cognitive impairment using information and communication technology. Clinical interventions in aging, 7, 539. 
Schikhof, Y., \& Mulder, I. (2008, November). Under watch and ward at night: design and evaluation of a remote monitoring system for dementia care. In Symposium of the Austrian HCI and Usability Engineering Group (pp. 475-486). Springer, Berlin, Heidelberg.

Schikhof, Y., Mulder, I., \& Choenni, S. (2010). Who will watch (over) me? Humane monitoring in dementia care. International Journal of Human-Computer Studies, 68(6), 410-422.

Schreiber, M., Lutz, K., Schweizer, A., Kalveram, K. T., \& Jaencke, L. (1998). Development and evaluation of an interactive computer-based training as arehabilitation tool for dementia. Development, 40.

Schwenk, M., Hauer, K., Zieschang, T., Englert, S., Mohler, J., \& Najafi, B. (2014). Sensor-derived physical activity parameters can predict future falls in people with dementia. Gerontology, 60(6), 483-492.

Shin, D., Shin, D., \& Shin, D. (2014). Ubiquitous health management system with watch-type monitoring device for dementia patients. Journal of Applied Mathematics, 2014.

Shore, L., Power, V., de Eyto, A. \& O’Sullivan, L.W. (2018). Technology acceptance and usercentred design of exoskeleton for older adults: a commentary. Robotics, 7, 3.

Shoval, N., Auslander, G. K., Freytag, T., Landau, R., Oswald, F., Seidl, U., ... \& Heinik, J. (2008). The use of advanced tracking technologies for the analysis of mobility in Alzheimer's disease and related cognitive diseases. BMC geriatrics, 8(1), 7.

Siewiorek, D., Smailagic, A., Furukawa, J., Krause, A., Moraveji, N., Reiger, K., ... \& Wong, F. L. (2003, October). Sensay: A context-aware mobile phone. In null (p. 248). IEEE.

Sim, K., Phua, C., Yap, G. E., Biswas, J., \& Mokhtari, M. (2011, August). Activity recognition using correlated pattern mining for people with dementia. In Engineering in Medicine and Biology Society, EMBC, 2011 Annual International Conference of the IEEE (pp. 7593-7597). IEEE.

Sixsmith, A., \& Johnson, N. (2004). A smart sensor to detect the falls of the elderly. IEEE Pervasive computing, (2), 42-47.

Sixsmith, A. J., Orpwood, R. D., \& Torrington, J. M. (2010). Developing a music player for people with dementia. Gerontechnology, 9(3), 421-427.

Skillen, K., Chen, L., Nugent, C. D., Donnelly, M. P., \& Solheim, I. (2012, August). A user profile ontology based approach for assisting people with dementia in mobile environments. In Engineering in Medicine and Biology Society (EMBC), 2012 Annual International Conference of the IEEE (pp. 6390-6393).

Skjerve, A., Bjorvatn, B., \& Holsten, F. (2004). Light therapy for behavioural and psychological symptoms of dementia. International Journal of Geriatric Psychiatry, 19(6), 516-522.

Smith, G. E., Lunde, A. M., Hathaway, J. C., \& Vickers, K. S. (2007). Telehealth home monitoring of solitary persons with mild dementia. American Journal of Alzheimer's Disease \& Other Dementias ${ }^{\circledR}, 22(1), 20-26$.

Smith, T. L., \& Toseland, R. W. (2006). The effectiveness of a telephone support program for caregivers of frail older adults. The Gerontologist, 46(5), 620-629.

Smyth, K. A., Rose, J. H., McClendon, M. J., \& Lambrix, M. A. (2007). Relationships among caregivers' demographic characteristics, social support ratings, and expectations of computermediated support groups. Journal of Applied Gerontology, 26(1), 58-77.

Sorri, L., Leinonen, E., \& Ervasti, M. (2011, June). Wayfinding aid for the elderly with memory disturbances. In ECIS (p. 137).

Spiekman, M. E., Haazebroek, P., \& Neerincx, M. A. (2011, November). Requirements and platforms for social agents that alarm and support elderly living alone. In International Conference on Social Robotics (pp. 226-235). Springer, Berlin, Heidelberg.

Spring, H. J., Rowe, M. A., \& Kelly, A. (2009). Improving caregivers' well-being by using technology to manage nighttime activity in persons with dementia. Research in gerontological nursing, 2(1), 39-48.

Sugihara, T., Fujinami, T., Jones, R., Kadowaki, K., \& Ando, M. (2015). Enhancing care homes with 
assistive video technology for distributed caregiving. AI \& society, 30(4), 509-518.

Sugihara, T., Fujinami, T., \& Miura, M. (2012, November). Approaches to incorporating assistive technologies into dementia care. In Soft Computing and Intelligent Systems (SCIS) and 13th International Symposium on Advanced Intelligent Systems (ISIS), 2012 Joint 6th International Conference on (pp. 685-690). IEEE.

Suijkerbuijk, S., Brankaert, R., de Kort, Y. A., Snaphaan, L. J., \& den Ouden, E. (2014). Seeing the first-person perspective in dementia: a qualitative personal evaluation game to evaluate assistive technology for people affected by dementia in the home context. Interacting with Computers, 27(1), 47-59.

Sun, M., Giroux, S., \& Pigot, H. (2006, August). Epitalk Advisor System in Smart Home Context. In Machine Learning and Cybernetics, 2006 International Conference on (pp. 2320-2323). IEEE.

Sung, M. S., Jang, H. J., Lee, K. W., \& Kim, Y. I. (2001). The Development and Effect of a CD ROM Based Caring Program for the Family Caregivers Amomg the Korean Demented Elderly. Journal of Korean Society of Medical Informatics, 7(1), 45-55.

Tamura, T., Yonemitsu, S., Itoh, A., Oikawa, D., Kawakami, A., Higashi, Y., ... \& Nakajima, K. (2004). Is an entertainment robot useful in the care of elderly people with severe dementia?. The Journals of Gerontology Series A: Biological Sciences and Medical Sciences, 59(1), M83-M85.

Tapus, A. (2009, July). Improving the quality of life of people with dementia through the use of socially assistive robots. In Advanced Technologies for Enhanced Quality of Life, 2009. ATEQUAL'09. (pp. 81-86). IEEE.

Tapus, A., Tapus, C., \& Mataric, M. J. (2009, June). The use of socially assistive robots in the design of intelligent cognitive therapies for people with dementia. In Rehabilitation Robotics, 2009. ICORR 2009. IEEE International Conference on (pp. 924-929). IEEE.

Taylor, F. (2005). Care managers' views on assistive technology. Journal of Dementia Care, 13(5), 32.

Topo, P. (2009). Technology studies to meet the needs of people with dementia and their caregivers: a literature review. Journal of Applied Gerontology, 28(1), 5-37.

Topo, P., Jylhä, M., \& Laine, J. (2002). Can the telephone-using abilities of people with dementia be promoted? An evaluation of a simple-to-use telephone. Technology and Disability, 14(1), 313.

Topo, P., Mäki, O., Saarikalle, K., Clarke, N., Begley, E., Cahill, S., ... \& Gilliard, J. (2004). Assessment of a music-based multimedia program for people with dementia. Dementia, 3(3), 331-350.

Topo, P., Saarikalle, K., Begley, E., Cahill, S., Holthe, T., \& Macijauskiene, J. (2007). " I don't know about the past or the future, but today it's Friday"-Evaluation of a time aid for people with dementia. Technology and Disability, 19(2, 3), 121-131.

Torkamani, M., McDonald, L., Aguayo, I. S., Kanios, C., Katsanou, M. N., Madeley, L., ... \& Jahanshahi, M. (2014). A randomized controlled pilot study to evaluate a technology platform for the assisted living of people with dementia and their carers. Journal of Alzheimer's Disease, 41(2), 515-523.

Torrington, J. (2009). The design of technology and environments to support enjoyable activity for people with dementia. ALTER-European Journal of Disability Research/Revue Européenne de Recherche sur le Handicap, 3(2), 123-137.

Tremont, G., Davis, J., Papandonatos, G. D., Grover, C., Ott, B. R., Fortinsky, R. H., ... \& Bishop, D. S. (2013). A telephone intervention for dementia caregivers: Background, design, and baseline characteristics. Contemporary clinical trials, 36(2), 338-347.

Tremont, G., Davis, J. D., Papandonatos, G. D., Ott, B. R., Fortinsky, R. H., Gozalo, P., ... \& Bishop, D. S. (2015). Psychosocial telephone intervention for dementia caregivers: A randomized, 
controlled trial. Alzheimer's \& Dementia, 11(5), 541-548.

Tremont, G., Duncan Davis, J., Bishop, D. S., \& Fortinsky, R. H. (2008). Telephone-delivered psychosocial intervention reduces burden in dementia caregivers. Dementia, 7(4), 503-520.

Tung, J. Y., Rose, R. V., Gammada, E., Lam, I., Roy, E. A., Black, S. E., \& Poupart, P. (2014). Measuring life space in older adults with mild-to-moderate Alzheimer's disease using mobile phone GPS. Gerontology, 60(2), 154-162.

Van Laerhoven, K., Schmidt, A., \& Gellersen, H. W. (2002). Multi-sensor context aware clothing. In Wearable Computers, 2002.(ISWC 2002). Proceedings. Sixth International Symposium on (pp. 49-56). IEEE.

Vuong, N. K., Chan, S., Lau, C. T., \& Lau, K. M. (2011, May). Feasibility study of a real-time wandering detection algorithm for dementia patients. In Proceedings of the First ACM MobiHoc Workshop on Pervasive Wireless Healthcare (p. 11). ACM.

Vuong, N. K., Goh, S. G. A., Chan, S., \& Lau, C. T. (2013, July). A mobile-health application to detect wandering patterns of elderly people in home environment. In Engineering in Medicine and Biology Society (EMBC), 2013 35th Annual International Conference of the IEEE (pp. 6748-6751). IEEE.

Wan, J., Byrne, C., O’Hare, G. M., \& O’Grady, M. J. (2010, September). OutCare: Supporting dementia patients in outdoor scenarios. In International Conference on Knowledge-Based and Intelligent Information and Engineering Systems (pp. 365-374). Springer, Berlin, Heidelberg.

Wang, R. H., Gorski, S. M., Holliday, P. J., \& Fernie, G. R. (2011). Evaluation of a contact sensor skirt for an anti-collision power wheelchair for older adult nursing home residents with dementia: Safety and mobility. Assistive Technology, 23(3), 117-134.

Wang, H., Zheng, H., Augusto, J. C., Martin, S., Mulvenna, M., Carswell, W., ... \& McSorley, K. (2010, December). Monitoring and analysis of sleep pattern for people with early dementia. In Bioinformatics and Biomedicine Workshops (BIBMW), 2010 IEEE International Conference on (pp. 405-410). IEEE.

Wettstein, M., Wahl, H. W., Shoval, N., Oswald, F., Voss, E., Seidl, U., ... \& Landau, R. (2015). Out-of-home behavior and cognitive impairment in older adults: findings of the SenTra Project. Journal of Applied Gerontology, 34(1), 3-25.

Wigg, J. M. (2010). Liberating the wanderers: using technology to unlock doors for those living with dementia. Sociology of health \& illness, 32(2), 288-303.

Williams, K., Arthur, A., Niedens, M., Moushey, L., \& Hutfles, L. (2013). In-home monitoring support for dementia caregivers: a feasibility study. Clinical nursing research, 22(2), 139150.

Wilson, B. A. (1997). Cognitive rehabilitation: How it is and how it might be. Journal of the International Neuropsychological Society, 3(05), 487-496.

Wilson, B. A. (2005). The theory and practice of neuropsychological rehabilitation: An overview. In Wilson, B. A. (Ed.), Neuropsychological rehabilitation: Theory and practice. CRC Press.

Wilson, B. A. (2008). Neuropsychological rehabilitation. Annual Review of Clinical Psychology, 4(1), 141-162.

Winson, R., Wilson, B. A., \& Bateman, A. (Eds.). (2017). The Brain Injury Rehabilitation Workbook. Guilford Publications.

Winter, L., \& Gitlin, L. N. (2007). Evaluation of a telephone-based support group intervention for female caregivers of community-dwelling individuals with dementia. American Journal of Alzheimer's Disease \& Other Dementias ${ }^{\circledR}, 21(6), 391-397$.

White, E. B., Montgomery, P., \& McShane, R. (2010). Electronic tracking for people with dementia who get lost outside the home: a study of the experience of familial carers. British Journal of Occupational Therapy, 73(4), 152-159. 
Wolden, H., Strand, G. V., \& Gjellestad, Å. (2006). Caregivers' perceptions of electric versus manual toothbrushes for the institutionalised elderly. Gerodontology, 23(2), 106-110.

Woodberry, E., Browne, G., Hodges, S., Watson, P., Kapur, N., \& Woodberry, K. (2015). The use of a wearable camera improves autobiographical memory in patients with Alzheimer's disease. Memory, 23(3), 340-349.

World Health Organization (1980) International Classification of Impairments, Disabilities, and Handicaps. A manual of classification relating to the consequence of disease. Geneva: World Health Organization

Wu, P., \& Miller, C. (2005). Results from a field study: The need for an emotional relationship between the elderly and their assistive technologies. Foundations of Augmented Cognition, 11, 889-898.

Xenakidis, C. N., Hadjiantonis, A. M., \& Milis, G. M. (2014, October). A Mobile Assistive Application for People with Cognitive Decline. In Interactive Technologies and Games (iTAG), 2014 International Conference on (pp. 28-35).

Yuginovich, T., \& Soar, J. (2014). Lean thinking in dementia care through smart assistive technology: an evaluation. In Lean Thinking for Healthcare (pp. 143-167). Springer, New York, NY.

Zarit, S. H., \& Edwards, A. B. (2008). Family caregiving: Research and clinical intervention. In R. T. Woods \& L. Clare (Eds.), Handbook of the clinical psychology of ageing (2nd ed.). (pp. 255-288). Chichester: John Wiley \& Sons Ltd.

Zhang, D., Hariz, M., \& Mokhtari, M. (2008, March). Assisting elders with mild dementia staying at home. In Pervasive Computing and Communications, 2008. PerCom 2008. Sixth Annual IEEE International Conference on (pp. 692-697).

Zhang, S., McClean, S., Scotney, B., Hong, X., Nugent, C., \& Mulvenna, M. (2008, June). Decision support for alzheimer's patients in smart homes. In Computer-Based Medical Systems, 2008. CBMS'08. 21 st IEEE International Symposium on (pp. 236-241). IEEE.

Zetzsche, C., Gerkensmeyer, T., Schmid, F., \& Schill, K. (2012, May). Sensorimotor Representation of Space: Application in Autonomous Systems and in a Wayfinding Assistant for Alzheimer's Disease. In Computer and Information Science (ICIS), 2012 IEEE/ACIS 11th International Conference on (pp. 219-224). IEEE. 


\section{Tables}

Table 1:

Conceptualization of technological solutions for PwD using a Neuropsychological Rehabilitation framework

\begin{tabular}{lrrr}
\hline & $\begin{array}{c}\text { Number of } \\
\text { purposes }\end{array}$ & $\begin{array}{l}\text { Percent of } \\
\text { purposes }\end{array}$ & $\begin{array}{l}\text { Percent of } \\
\text { studies }\end{array}$ \\
\hline compensation & 131 & 42 & 52 \\
environment modification & 19 & 6 & 8 \\
cognitive retraining & 18 & 6 & 7 \\
monitoring & 84 & 27 & 33 \\
carer support & 33 & 11 & 13 \\
activity recognition & 27 & 9 & 10 \\
other & 3 & 1 & 1 \\
\hline
\end{tabular}

Table 2:

Cognitive functions commonly targeted by different technological solution purposes.

\begin{tabular}{lccccc}
\hline & $\begin{array}{c}\text { Total } \\
\text { studies }\end{array}$ & Compensate & $\begin{array}{c}\text { Environment } \\
\text { Modification }\end{array}$ & $\begin{array}{c}\text { Cognitive } \\
\text { retrain }\end{array}$ & Monitor \\
\hline Time and place orientation & 87 & 42 & 16 & 2 & 52 \\
Sequencing complex actions & 52 & 51 & 0 & 0 & 1 \\
Memory & 47 & 40 & 9 & 2 & 10 \\
Communication & 44 & 44 & 0 & 0 & 0 \\
Balance & 14 & 8 & 1 & 0 & 8 \\
General cognition & 8 & 1 & 0 & 10 & 1 \\
Attention & 2 & 0 & 0 & 2 & 0 \\
\hline
\end{tabular}


Table 3:

Impaired functions and disabilities/activities commonly targeted by compensatory technological solutions $^{1}$

\begin{tabular}{cc}
\hline Impaired Function & $\mathrm{n}$ \\
Disability/Activity & 51 \\
\hline Sequencing Complex Actions & 31 \\
leisure (music - watching TV) & 19 \\
cooking & 17 \\
bathroom routine & 5 \\
making drinks & 4 \\
getting dressed & 3 \\
table setting & 2 \\
drinking water & 2 \\
shopping & 40 \\
Memory & 29 \\
keeping routines & 12 \\
finding objects & 12 \\
taking medication & 7 \\
remembering & 44 \\
Communication & 26 \\
making a phone call & 17 \\
talking & 42 \\
Time and Place Orientation & 16 \\
keeping time & 12 \\
indoor wayfinding & 11 \\
sleeping & 5 \\
indoor wayfinding & 5 \\
outdoor wayfinding & 8 \\
Balance & 8 \\
walking & $p u r p$ \\
\hline
\end{tabular}

${ }^{1}$ Total number of studies with compensatory purpose: 131

Table 4:

Impaired functions and disabilities/activities commonly targeted by technological solutions that modify the environment ${ }^{1}$

\begin{tabular}{lc}
\hline Impaired Function & $\mathrm{n}$ \\
Disability/Activity & 16 \\
\hline Orientation in time & 14 \\
sleep & 9 \\
Memory & 9 \\
cooking & 1 \\
keeping routine & 1 \\
Balance & 1 \\
walking &
\end{tabular}

${ }^{1}$ Total number of studies with a focus on modification of environment: 19 
Table 5:

Impaired functions and disabilities/activities commonly targeted by monitoring technological solutions $^{1}$

\begin{tabular}{lc}
\hline Impaired Function & $\mathrm{n}$ \\
Disability/Activity & 42 \\
\hline Orientation place & 23 \\
wayfinding out-house & 14 \\
wayfinding in-house & 4 \\
non-specified wayfinding & 6 \\
Alarm when compensation fails & 11 \\
Orientation in time & 8 \\
sleep & 3 \\
Alarm when compensation fails & 10 \\
Memory & 1 \\
medication & 8 \\
Alarm when compensation fails & 8 \\
Balance & 8 \\
walking & 2 \\
sleep (reduce falling when waking-up) & 3 \\
Alarm when compensation fails & 1 \\
Self-regulation & 1 \\
challenging behaviors & 1 \\
Sequencing complex actions & 1 \\
hand washing &
\end{tabular}

${ }^{1}$ Total number of studies with monitoring purpose: 84

Table 6:

Impaired cognitive functions commonly targeted by retraining technological solutions ${ }^{1}$

\begin{tabular}{lr}
\hline Impaired function & $\mathrm{n}$ \\
\hline general cognition - non-specified & 10 \\
attention & 2 \\
spatial knowledge & 2 \\
memory & 2 \\
\hline
\end{tabular}

${ }^{1}$ Total number of studies with cognitive retraining purpose: 18 
Table 7:

Features and aims of factors related to enhanced engagement with technologies

\begin{tabular}{|c|c|c|}
\hline Factor & Features & Aim of adaptation/design \\
\hline \multirow{11}{*}{$\begin{array}{l}\text { Factors related to } \\
\text { the technology }\end{array}$} & Simplicity & - Reduce cognitive demands \\
\hline & Reliability & $\begin{array}{l}\text { - Reduce cognitive demands } \\
\text { - Reduce anxiety }\end{array}$ \\
\hline & Intuitiveness & - Reduce cognitive demands \\
\hline & Cognition-enhancing & - Leverage cognitive strengths \\
\hline & Not bulky & $\begin{array}{l}\text { - Facilitate portability } \\
\text { - Facilitate concealability }\end{array}$ \\
\hline & Portability & - Facilitate easiness to carry \\
\hline & Concealability & - Avoid looking different \\
\hline & Familiarity & $\begin{array}{l}\text { - Promote intuitiveness } \\
\text { - Promote concealability }\end{array}$ \\
\hline & $\begin{array}{l}\text { Customizability of contents } \\
\text { and their delivery format } \\
\text { according to PwD's personal } \\
\text { information }\end{array}$ & $\begin{array}{l}\text { - Generate positive emotions } \\
\text { - Reduce confusion } \\
\text { - Reduce anxiety }\end{array}$ \\
\hline & $\begin{array}{l}\text { Human-like social interaction } \\
\text { capabilities }\end{array}$ & $\begin{array}{l}\text { - Generate positive emotions } \\
\text { - Reduce confusion } \\
\text { - Reduce anxiety } \\
\text { - Promote feelings of safety }\end{array}$ \\
\hline & $\begin{array}{l}\text { Adaptability to state of PwD } \\
\text { and/or environment }\end{array}$ & $\begin{array}{l}\text { - Promote feelings of self-efficacy } \\
\text { - Regulate PwD's psychological } \\
\text { states (e.g. frustration and anxiety) }\end{array}$ \\
\hline \multirow[t]{2}{*}{$\begin{array}{l}\text { Factors related to } \\
\text { the carer }\end{array}$} & $\begin{array}{l}\text { Capacity to decide on behalf } \\
\text { of PwD regarding technology } \\
\text { to adopt }\end{array}$ & $\begin{array}{l}\text { - Determine what the PwD's needs } \\
\text { are and which technological } \\
\text { solutions are more suitable to tackle } \\
\text { these needs } \\
\text { - Determine what are the PwD's } \\
\text { abilities to use technology, etc.) }\end{array}$ \\
\hline & $\begin{array}{l}\text { Capacity to facilitate the use } \\
\text { of the chosen technology }\end{array}$ & $\begin{array}{l}\text { - Facilitate the use of technology } \\
\text { once it is adopted (e.g. reinforce its } \\
\text { use; seek help from professionals } \\
\text { when there are problems or } \\
\text { technological solutions need to be } \\
\text { adjusted; etc.). }\end{array}$ \\
\hline
\end{tabular}




\section{Figures}

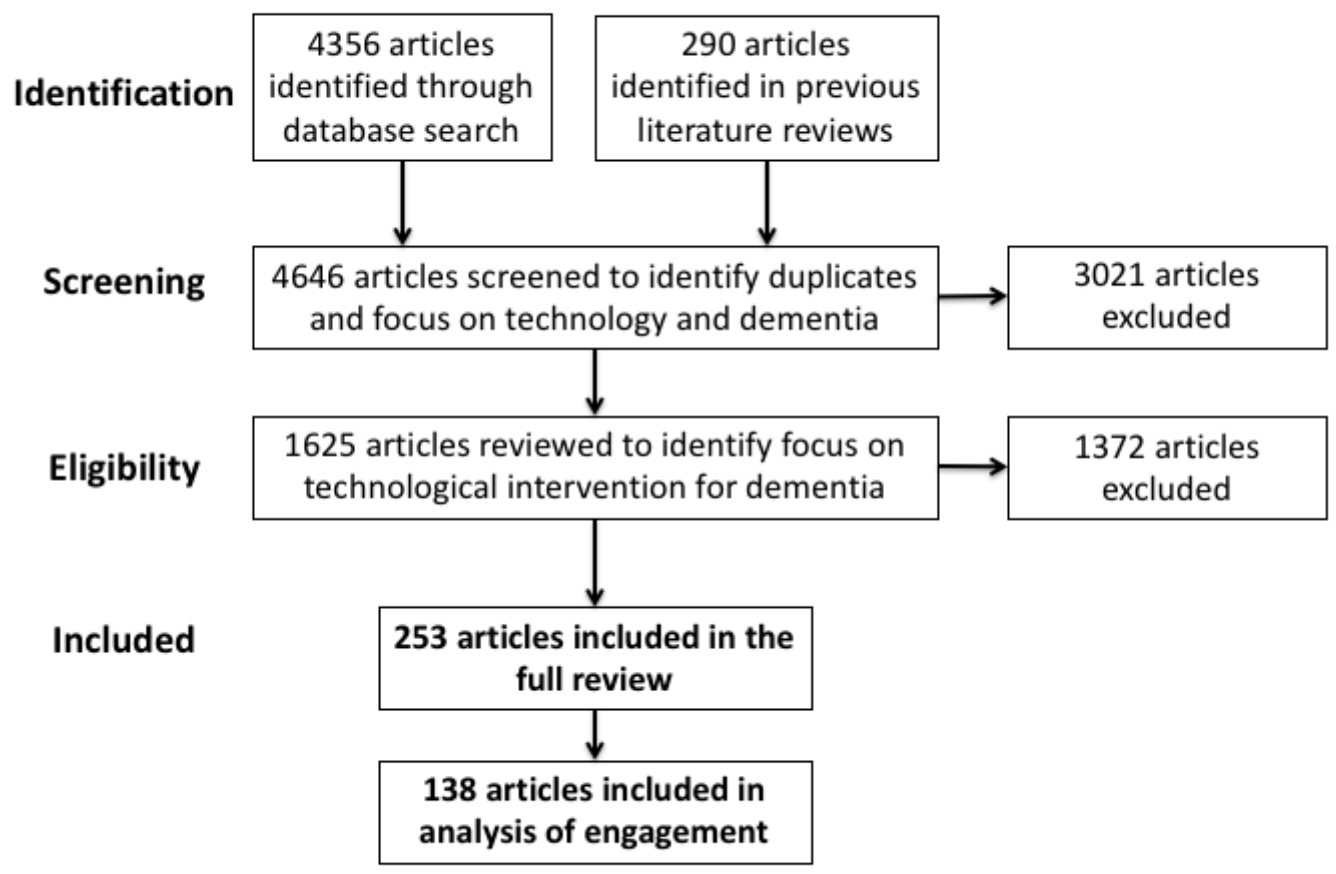

Fig. 1. Process of identification and selection of studies

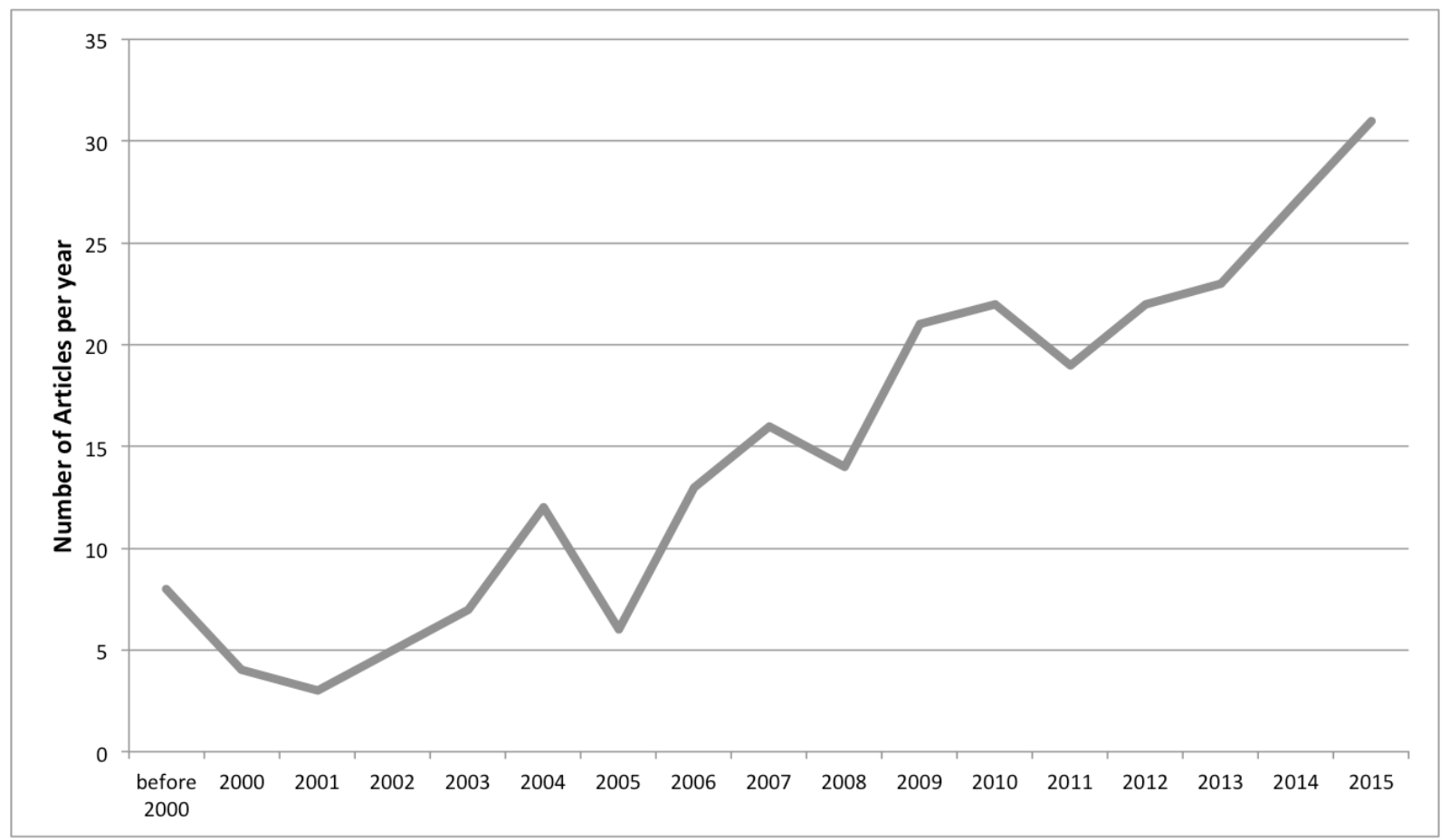

Fig. 2. The evolution of research on technological solutions for PwD from 2003 to 2015 


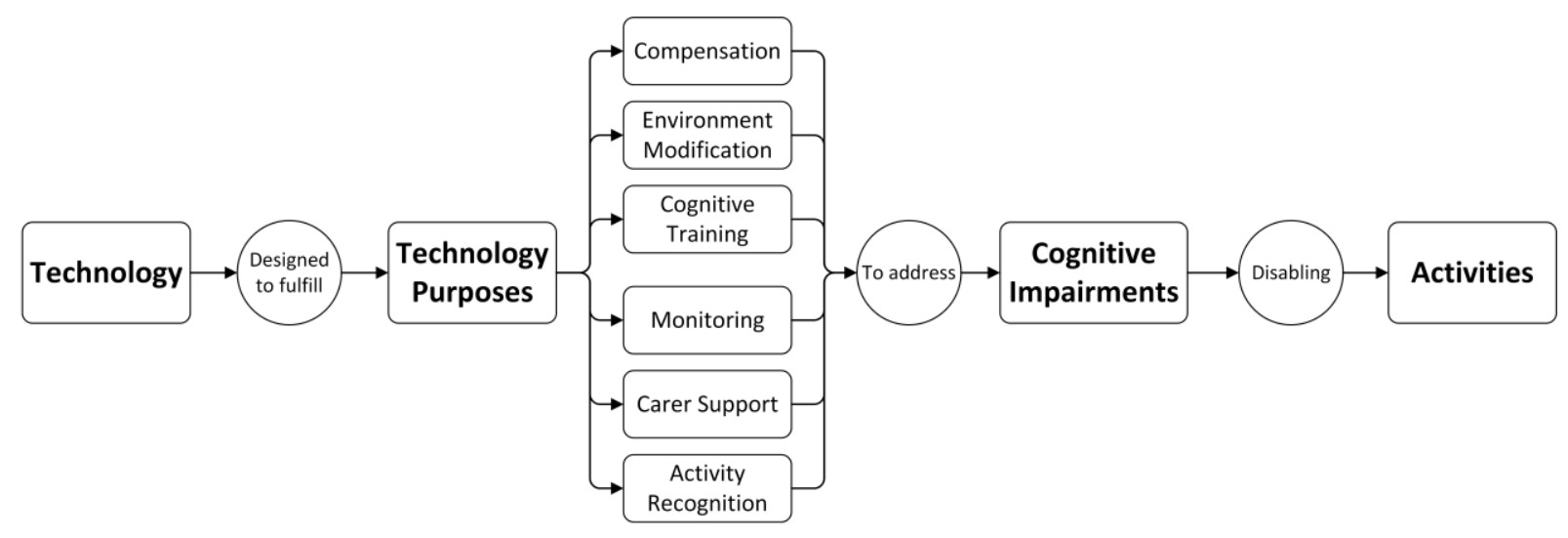

Fig. 3. Neuropsychological Rehabilitation-based schema for the systematic analysis of dementia technologies

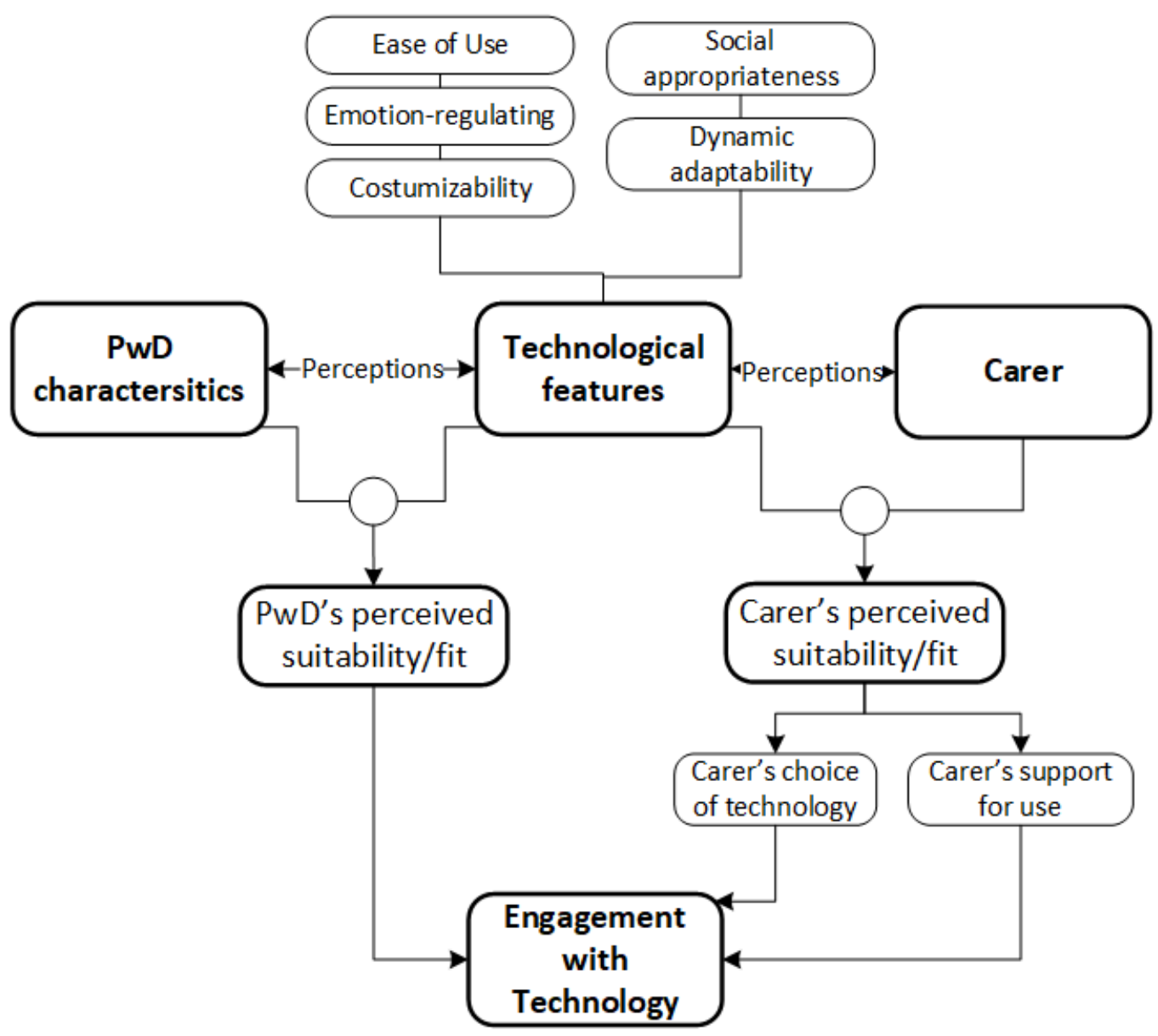

Figure 4: Factors influencing the use of technology 


\section{Disclosure Statement}

The authors of this paper report no conflict of interests 